\title{
Resilience, Adaptation, and Sustainability Plan Assessment Methodology: An Annotated Bibliography
}

Christopher Clavin Avery D'Abreau Emily H. Walpole 


\title{
Resilience, Adaptation, and Sustainability Plan Assessment Methodology: An Annotated Bibliography
}

\author{
Christopher Clavin \\ Avery D'Abreau \\ Emily H. Walpole \\ Materials and Structural Systems Division \\ Engineering Laboratory
}

This publication is available free of charge from:

https://doi.org/10.6028/NIST.TN.2117

September 2020

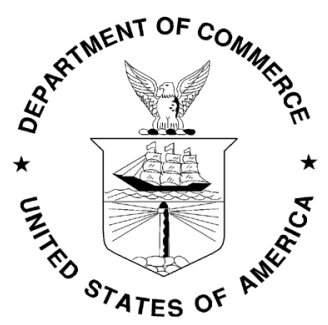

U.S. Department of Commerce

Wilbur L. Ross, Jr., Secretary

National Institute of Standards and Technology Walter Copan, NIST Director and Undersecretary of Commerce for Standards and Technology 
Certain commercial entities, equipment, or materials may be identified in this document in order to describe an experimental procedure or concept adequately. Such identification is not intended to imply recommendation or endorsement by the National Institute of Standards and Technology, nor is it intended to imply that the entities, materials, or equipment are necessarily the best available for the purpose.

National Institute of Standards and Technology Technical Note 2117 Natl. Inst. Stand. Technol. Tech. Note 2117, 83 pages (September 2020) CODEN: NTNOEF

This publication is available free of charge from: https://doi.org/10.6028/NIST.TN.2117 


\begin{abstract}
In the United States, preparing for the impacts of natural hazards is primarily the responsibility of communities and local governments. Increasingly, while communities address these hazard mitigation responsibilities, they are concurrently undertaking emerging planning processes that address objectives such as resilience, adaptation, and sustainability. These planning objectives require a process that may be technically and administratively complicated, often requiring the incorporation of emerging scientific information and decision making under uncertainty. The growth of these planning documents in practice and a field of scholarly work assessing the quality of these planning documents provides an opportunity to better understand how to increase the quality of these planning processes. This annotated bibliography was assembled to achieve two objectives: (1) to provide a review of scholarly literature assessing or evaluating community or local scale planning for objectives related to resilience, adaptation, and sustainability, and (2) to inform the future development of an analytical methodology to assess the content of resilience, adaptation, and sustainability planning guidance, instructions, and requirements for practice. A discussion of the review findings addresses the second objective by presenting a set of plan quality principles that can be used for future plan and associated material assessment. The discussion also highlights concepts observed related to resilience, adaptation, and sustainability terminology, and findings from the review related to the state of practice and research on resilience, adaptation, and sustainability planning. Future areas of work to advance research capabilities related to plan quality assessment are also presented.
\end{abstract}

Keywords: Community planning; urban planning; community resilience; assessment; resilience; adaptation; sustainability; hazards; mitigation 


\section{Table of Contents}

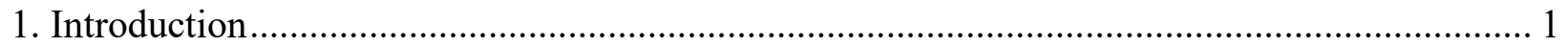

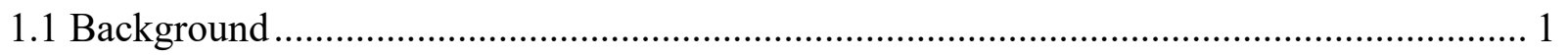

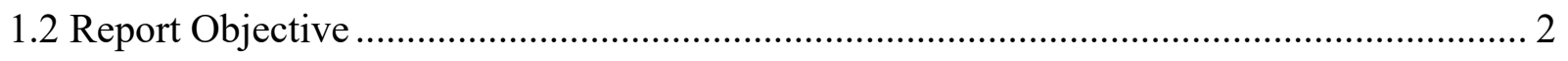

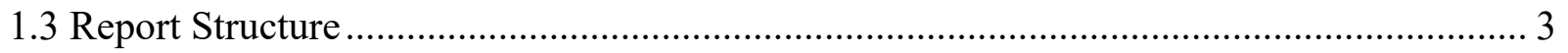

2. Article Selection and Annotated Bibliography Organization ..................................................... 4

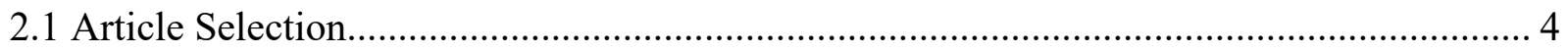

2.2 Annotated Bibliography Organization.......................................................................... 5

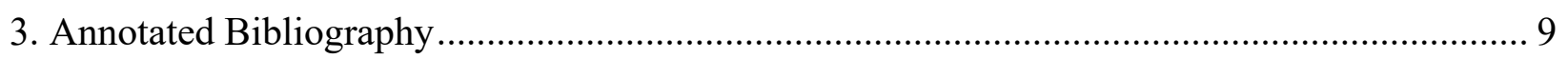

3.1 Plan Evaluation Studies and Methodology Examinations ................................................ 9

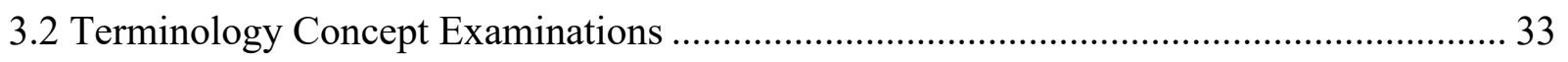

3.3 State of Practice, Implementation, or Research Examinations ........................................... 47

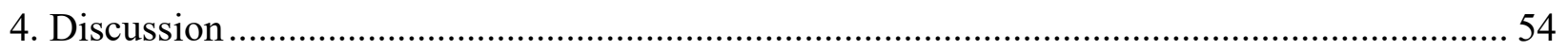

4.1 Overview of Results and Themes Observed ................................................................ 54

4.1.1 Plan Evaluation Studies and Methodology Examination............................................ 54

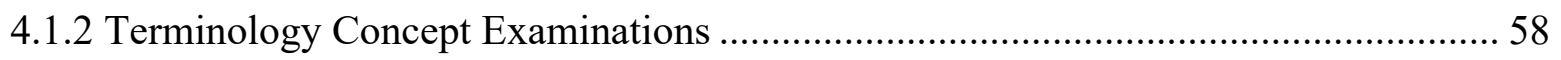

4.1.3 State of Practice, Implementation, or Research Examinations ................................... 59

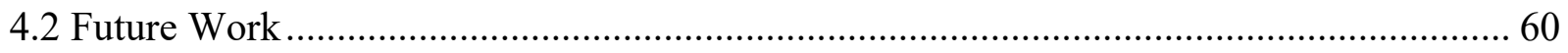

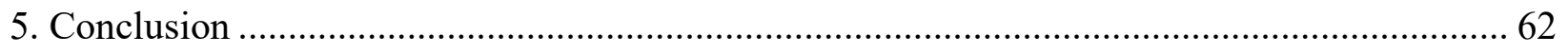

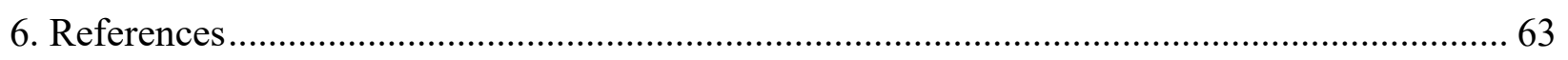

Appendix A - Full Listing of Articles Identified in Web of Science Query .................................. 69

\section{List of Tables}

Table 1. Web of Science categories used for screening of structured queries................................. 4

Table 2. List of annotated articles by order of appearance ...................................................... 7

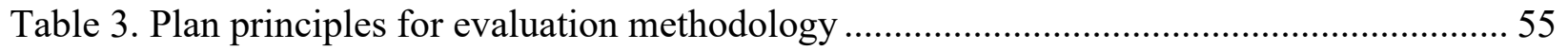




\section{Annotated Bibliography Articles Table of Contents}

1. Baker, Ingrid, Ann Peterson, Gregory Brown, and Clive Mcalpine. "Local Government Response to the Impacts of Climate Change: An Evaluation of Local Climate Adaptation Plans." Landscape and Urban Planning 107 (August 1, 2012): 127136

2. Berke, Philip R., and Maria Manta Conroy. "Are We Planning for Sustainable Development?" Journal of the American Planning Association 66, no. 1 (March 31, 2000): 21-33.

3. Berke, Philip, John Cooper, Meghan Aminto, Shannon Grabich, and Jennifer Horney. "Adaptive Planning for Disaster Recovery and Resiliency: An Evaluation of 87 Local Recovery Plans in Eight States." Journal of the American Planning Association 80, no. 4 (October 2, 2014): 310-23.

4. Berke, Philip, and David Godschalk. "Searching for the Good Plan: A MetaAnalysis of Plan Quality Studies.” Journal of Planning Literature, February 1, 2009 .... 13

5. Berke, Philip R., Ward Lyles, and Gavin Smith. "Impacts of Federal and State Hazard Mitigation Policies on Local Land Use Policy:” Journal of Planning Education and Research, January 16, 2014.

6. Berke, P., G. Smith, and W. Lyles. "Planning for Resiliency: Evaluation of State Hazard Mitigation Plans under the Disaster Mitigation Act." Natural Hazards Review 13, no. 2 (May 2012): 139-49.

7. Birkmann, Jörn, and Korinna von Teichman. "Integrating Disaster Risk Reduction and Climate Change Adaptation: Key Challenges-Scales, Knowledge, and Norms." Sustainability Science 5, no. 2 (July 1, 2010): 171-84.....

8. Feinberg, Daniel S., and Clare M. Ryan. "Evaluating the Quality and Implementation of Hazard Mitigation Plans in Coastal Washington State.” Natural Hazards Review 21, no. 2 (May 1, 2020): 04020013.

9. Hu, Q., Z. H. Tang, L. Zhang, Y. Y. Xu, X. L. Wu, and L. G. Zhang. "Evaluating Climate Change Adaptation Efforts on the US 50 States' Hazard Mitigation Plans." Natural Hazards 92, no. 2 (June 2018): 783-804.

10. Lyles, W., P. Berke, and G. Smith. “A Comparison of Local Hazard Mitigation Plan Quality in Six States, USA.” Landscape and Urban Planning 122 (February 2014): 8999.

11. Preston, Benjamin L., Richard M. Westaway, and Emma J. Yuen. "Climate Adaptation Planning in Practice: An Evaluation of Adaptation Plans from Three Developed Nations." Mitigation and Adaptation Strategies for Global Change 16, no. 4 (April 2011): 407-38. 
12. Schrock, Greg, Ellen M. Bassett, and Jamaal Green. "Pursuing Equity and Justice in a Changing Climate: Assessing Equity in Local Climate and Sustainability Plans in U.S. Cities." Journal of Planning Education and Research 35, no. 3 (September 1, 2015): 28295.

13. Stults, M., and S. C. Woodruff. "Looking under the Hood of Local Adaptation Plans: Shedding Light on the Actions Prioritized to Build Local Resilience to Climate Change." Mitigation and Adaptation Strategies for Global Change 22, no. 8 (December 2017): 1249-79.

14. Woodruff, S. C., and M. Stults. "Numerous Strategies but Limited Implementation Guidance in US Local Adaptation Plans.” Nature Climate Change 6, no. 8 (August 2016): 796-+. 28

15. Woodruff, Sierra C., Sara Meerow, Missy Stults, and Chandler Wilkins. "Adaptation to Resilience Planning: Alternative Pathways to Prepare for Climate Change." Journal of Planning Education and Research, October 4, 2018, 0739456X18801057.

16. Davidson, J. L., C. Jacobson, A. Lyth, A. Dedekorkut-Howes, C. L. Baldwin, J. C. Ellison, N. J. Holbrook, et al. "Interrogating Resilience: Toward a Typology to Improve Its Operationalization.” Ecology and Society 21, no. 2 (2016). 33

17. Folke, Carl, Stephen R. Carpenter, Brian Walker, Marten Scheffer, Terry Chapin, and Johan Rockstrom. "Resilience Thinking: Integrating Resilience, Adaptability and Transformability." Ecology and Society 15, no. 4 (2010): 20. 34

18. Lei, Yongdeng, Jing'ai Wang, Yaojie Yue, Hongjian Zhou, and Weixia Yin. "Rethinking the Relationships of Vulnerability, Resilience, and Adaptation from a Disaster Risk Perspective.” Natural Hazards 70, no. 1 (January 1, 2014): 609-27. 35

19. Meerow, S., and J. P. Newell. "Resilience and Complexity A Bibliometric Review and Prospects for Industrial Ecology.” Journal of Industrial Ecology 19, no. 2 (April 2015): 236-51.

20. Meerow, S., J. P. Newell, and M. Stults. "Defining Urban Resilience: A Review." Landscape and Urban Planning 147 (March 2016): 38-49. 38

21. Meerow, S., and M. Stults. "Comparing Conceptualizations of Urban Climate Resilience in Theory and Practice.” Sustainability 8, no. 7 (July 2016). 40

22. Moser, S., S. Meerow, J. Arnott, and E. Jack-Scott. "The Turbulent World of Resilience: Interpretations and Themes for Transdisciplinary Dialogue." Climatic Change 153, no. 1-2 (March 2019): 21-40. https://doi.org/10.1007/s10584-018-2358-0.

23. Romero-Lankao, P., D. M. Gnatz, O. Wilhelmi, and M. Hayden. "Urban Sustainability and Resilience: From Theory to Practice." Sustainability 8, no. 12 (December 2016).

24. Wied, M., J. Oehmen, and T. Welo. "Conceptualizing Resilience in Engineering Systems: An Analysis of the Literature.” Systems Engineering 23, no. 1 (January 2020): $3-13$ 
25. Bierbaum, R., J. B. Smith, A. Lee, M. Blair, L. Carter, F. S. Chapin, P. Fleming, et al. "A Comprehensive Review of Climate Adaptation in the United States: More than before, but Less than Needed." Mitigation and Adaptation Strategies for Global Change 18, no. 3 (March 2013): 361-406.

26. Koliou, Maria, John W. van de Lindt, Therese P. McAllister, Bruce R. Ellingwood, Maria Dillard, and Harvey Cutler. "State of the Research in Community Resilience: Progress and Challenges." Sustainable and Resilient Infrastructure 5, no. 3 (May 3, 2020): 131-51.

27. B Perkins, D Ojima, R Corell. "A Survey of Climate Change Adaptation Planning." Heinz Center, 2007. 50

28. Sellberg, My M., Cathy Wilkinson, and Garry D. Peterson. "Resilience Assessment: A Useful Approach to Navigate Urban Sustainability Challenges." Ecology and Society 20, no. 1 (2015): 43 


\section{Introduction}

\subsection{Background}

In the United States, preparing for the impacts of natural hazards is the primary responsibility of communities and local governments, often with technical or financial support from the state and federal government. Initiatives promoted by governments (at various scales) have encouraged local governments to take proactive measures to establish plans that mitigate the risks posed by natural hazards on communities, namely their physical infrastructure systems (FEMA 2020a, b, U. S. Global Change Research Program 2020, HUD 2020a, b, EDA 2020). Over the past 10 years to 15 years, U.S. based communities have taken action to address these measures, but also have incorporated various other goals and objectives into their public planning efforts (Bierbaum et al. 2013, Woodruff et al. 2018, Berke, Lyles, and Smith 2014, Berke, Smith, and Lyles 2012, Hu et al. 2018, Stults and Woodruff 2017). These efforts have included objectives such as increasing community resilience through efforts to understand interdependencies and relationships between a community's social and physical systems (i.e., community resilience planning; hazard mitigation planning), preparing communities to adapt to the effects of climate change (i.e., climate change adaptation planning), and increasing the environmental sustainability of the community (i.e., sustainability planning). These concepts, resilience, adaptation, and sustainability, are hereafter referred to as "RAS" topics.

While there may be distinct differences among the objectives or outcomes desired for each of these planning efforts, they each represent public planning processes that attempt to:

- Structure information about naturally occurring phenomena in a historical context or projected changes into the future,

- Influence investments or design elements of a community's built environment, services, or functions;

- Describe a structured decision making process to establish priorities; and

- Provide an objective basis for communicating goals, objectives, and implementing solutions to achieve these planning objectives.

The NIST Community Resilience Planning Guide, hereafter referred to as the Guide, is an example of a community oriented planning guidance document that provides a structured, six step methodology to design and implement a participatory planning process to establish community resilience goals, understand the relationships between a community's social functions and its built environment, support decision making on actions to achieve goals and address vulnerabilities, and implement a plan to support the outcomes of increasing resilience to hazards (National Institute of Standards and Technology 2016). Observations from implementation of the Guide by communities in the United States (Dillard, Helgeson, and Cauffman 2018), as well as other initiatives to support resilience planning (The Nature Conservancy, The Rockefeller Foundation 2020), reflect that communities are concurrently attempting to address and achieve outcomes that enhance their resilience to natural hazards (and other shocks or stressors), sustainability, and ability to adapt to the effects of climate change. Communities may not be making distinctions between these various types of objectives, as 
community officials with various backgrounds and skill sets are tasked to conduct all of these types of planning activities (e.g., planners, emergency management officials, sustainability officers, resilience officers).

While communities may be seizing opportunities to proactively plan for multiple objectives (i.e., resilience, sustainability, and/or adaptation), inconsistencies in planning processes, miscommunication about planning objectives, and inefficiencies in planning for multiple objectives may affect the ability of communities to translate planning documents into tangible projects or administrative solutions. Additionally, while complementary planning objectives are desired, there also may be adverse outcomes where one element of resilience, adaptation, or sustainability planning may be incompatible or detrimental to another planning objective, resulting in maladaptation or a failure to meet individual project goals.

There is a growing field of research that assesses plan quality, characterizes the elements of plans, and attributes the elements of plans to underlying community characteristics or planning process inputs (e.g., technical assistance, involvement of planning professionals, etc.) across RAS topics. Analytical methodologies demonstrated in this field of research allow for a systematic evaluation of plan contents, whereby the elements of plans and the planning processes described within can be compared objectively, and conclusions can be drawn about the observed similarities, the differences, and the underlying context of planning.

The methods, analytical approaches, and plan quality assessment findings from prior research provide a basis for developing an examination of where resilience, adaptation, and sustainability planning may be complementary or incompatible. Accordingly, the findings of the research presented in this Technical Note are intended to inform the scope and methods applied in future NIST research that will: (1) assess the content of previously published community-focused RAS planning guidance documents, and (2) elicit community RAS planners expectations and their use of technical planning guidance in RAS planning processes (see second report objective below).

\subsection{Report Objective}

This annotated bibliography was assembled to examine prior scholarly research on plan assessment methodologies that have been applied to local resilience, adaptation, and sustainability plans, and to examine conceptual frameworks that describe the alignment between these topics. Specifically, this report seeks to address two objectives:

1. Provide a review of scholarly literature assessing or evaluating community or local scale plans for objectives related to resilience, adaptation, and sustainability, and

2. Inform the future development of an analytical methodology to assess the content of resilience, adaptation, and sustainability planning guidance, instructions, and requirements for practice.

In the selection and review of articles in this annotated bibliography, an examination of common categories, elements, or criteria related to community scale planning related to resilience, 
adaptation, and sustainability objectives is conducted. While this annotated bibliography focuses on the terms resilience, adaptation, and sustainability, a uniform definition of these terms is not assumed a priori and identifying characteristics of terminology definitions was a desired feature of selected literature. A community scale focus is present in all of the articles examined, although some articles also review planning efforts at larger scales (e.g., national, international). To support the second objective, the studies included in the annotated bibliography examine community scale planning from the perspective of the various types of inputs, information, stakeholders, processes, and objectives/goals. Based on this, annotated bibliography entries describe typologies of concepts, terms, planning process elements, or planning process outputs that could be utilized to develop a broader planning assessment analytical methodology.

\subsection{Report Structure}

This annotated bibliography report is organized into five chapters. This first introductory chapter provides a background discussion and overview of the concepts explored and the objectives of the report. Chapter 2 provides a discussion of the article identification and selection process utilized, and provides a thematic organizational structure for the subsequent chapters. Chapter 3 includes the annotated bibliography entries, of which each includes a discussion of the study's purpose, methodologies presented, typologies of concepts related to resilience, adaptation, or sustainability planning, and a summary of the results and conclusions of the article. Chapter 4 presents a discussion of common themes, methods, or findings presented in the articles reviewed, and a brief discussion of future research identified in the literature review. Lastly, Chapter 5 provides a concluding discussion that recaps the objectives of the annotated bibliography, summarizes major themes identified, and observations from the literature review related to enhancing the research and practice of integrated resilience, adaptation, and sustainability planning. 


\section{Article Selection and Annotated Bibliography Organization}

\subsection{Article Selection}

This annotated bibliography includes scholarly literature that either provides a conceptual review and discussion of resilience (which includes topics such as disaster risk reduction and hazard mitigation), adaptation (which primarily relates to adapting to the impacts of climate change), and sustainability (which primarily relates to environmental sustainability), or presents methodologies and the results of assessments or evaluations of community scale plans on these topics. These two foci were selected for this annotated bibliography and associated literature review to achieve the second objective of the report: informing the future development of an analytical methodology to assess the content of resilience, adaptation, and sustainability planning guidance, instructions, and requirements for practice.

The articles selected were identified through two approaches: utilizing a structured set of queries of Web of Science's Core Collection and reviewing associated cited references or subject matter experts referrals to articles on RAS plan assessment and evaluation. This article selection took place in May and June 2020. The article section process involved utilizing search terms or keywords in the Web of Science database (see terms below). For query results that returned greater than approximately 150 articles, a series of Web of Science categories was used to screen articles that are most relevant to this annotated bibliography (see Table 1), and abstracts were reviewed for the remainder of articles. The abstracts were reviewed for the article's applicability to community or local scale planning on resilience, adaptation, sustainability, hazard mitigation, or disaster risk reduction planning, including theoretical discussions of concepts, plan quality assessment studies, and methodology or meta analyses studies.

Table 1. Web of Science categories used for screening of structured queries

\begin{tabular}{|l|l|}
\hline - environmental sciences & - urban studies \\
- environmental studies & - regional urban planning \\
- green sustainable science technology & - geography \\
- engineering multidisciplinary & - multidisciplinary sciences \\
- ecology & - social sciences interdisciplinary \\
- engineering civil & - transportation \\
- engineering environmental & - transportation science technology \\
- geography physical & \\
\hline
\end{tabular}

The search terms utilized for article identification include the following: "local climate plan evaluation" (327 results, 228 after category screening), "local adaptation plan evaluation" (186 results, 99 after category screening), "local resilience plan evaluation" (81 results, no category screening), "local mitigation plan evaluation" (156 results, no category screening), "local sustainability plan evaluation" (312 results, 198 after category screening). After reviewing abstracts for relevance to the objectives of the report, 60 topically relevant articles were identified, of which a final set of 28 articles (see Table 2, next section) were selected for inclusion in this annotated bibliography based on their relevance toward informing the 
development of an analytical methodology to assess the content of resilience, adaptation, and sustainability planning guidance, and contained typologies or enumerated categories that could inform future planning assessment instrument development. Appendix A provides a full listing of the 60 articles identified after screening and abstract review, including the 28 articles reviewed for this annotated bibliography.

\subsection{Annotated Bibliography Organization}

Articles are organized into three categories based on the primary article focus and the type of information that the article provides for understanding methodologies used to examine resilience, sustainability, and adaptation planning. While the 28 selected articles have been grouped into one of three discrete categories, many articles have wide ranging discussions, provide background content and discussion, or present information beyond the scope of the categories used in this annotated bibliography. Additionally, the first category was the primary focus of the annotated bibliography, given the report's objectives. The literature collected in the second and third category, however, were identified as relevant and useful for the overall bibliography. As a result, these categories are presented primarily for the purpose of organizing the literature and associated discussion (Chapter 4), but should not be considered an exhaustive review of all scholarly literature on the topics represented in each of the categories. For all articles, the literature review identified typologies (i.e., terms, definitions, and their relationships) of RAS related concepts.

There are three categories used for organizing the annotated bibliography:

1. Plan evaluation studies and methodology examinations: These articles systematically evaluate the elements of a written planning document created to achieve objectives related to resilience, sustainability, or adaptation. The evaluation often utilizes a qualitative content analysis approach but may also incorporate other analytical methods (qualitative and/or quantitative, including statistical analysis methods) to correlate observed plan quality principles with contextual community factors or other interventions. The articles may also present a proposal for how to advance methods that support robust plan evaluation across multiple types of plans and plan objectives.

2. Terminology concept examinations: These articles present various definitions of resilience, sustainability, and adaptation, and associated underlying characteristics of each. These articles may utilize both a single philosophical approach to specifying a definition (e.g., RAS from the perspective of socio-ecological systems) or present an examination crossing multiple scientific fields or fields of practice (e.g., engineering, psychology, ecology, urban planning). These articles utilize a literature review to develop their findings. While synthesizing the results of these articles is not the main goal of this report (and not meant to represent a complete collection of this type of work), they were identified during the article section process and contribute knowledge relevant to research on the intersection of resilience, adaptation, and sustainability. 
3. State of practice, implementation, or research examinations: These articles present the findings of a research study on the state of RAS plan implementation, policy analysis related to RAS topics, or provide an overview on the state of research supporting advances in RAS planning and associated implementation. These articles base their findings on prior plan or research efforts, review the state of practice or research, and describe future efforts that are needed to advance the practice or policy related to RAS planning or research supporting RAS planning topics. 
Table 2. List of annotated articles by order of appearance

\begin{tabular}{|c|c|c|c|}
\hline Author(s) & Year & Title & $\begin{array}{l}\text { Journal or } \\
\text { Publisher }\end{array}$ \\
\hline \multicolumn{4}{|c|}{ Plan evaluation studies and methodology examinations } \\
\hline $\begin{array}{l}\text { Baker, I., A. Peterson, G. } \\
\text { Brown, and C. Mcalpine }\end{array}$ & 2012 & $\begin{array}{l}\text { "Local Government Response to the Impacts of } \\
\text { Climate Change: An Evaluation of Local } \\
\text { Climate Adaptation Plans." }\end{array}$ & $\begin{array}{l}\text { Landscape and Urban } \\
\text { Planning }\end{array}$ \\
\hline $\begin{array}{l}\text { Berke, P.R., and M. Manta } \\
\text { Conroy }\end{array}$ & 2000 & $\begin{array}{l}\text { “Are We Planning for Sustainable } \\
\text { Development?" }\end{array}$ & $\begin{array}{l}\text { Journal of the } \\
\text { American Planning } \\
\text { Association }\end{array}$ \\
\hline $\begin{array}{l}\text { Berke, P.R., J. Cooper, M. } \\
\text { Aminto, S. Grabich, and J. } \\
\text { Horney }\end{array}$ & 2014 & $\begin{array}{l}\text { "Adaptive Planning for Disaster Recovery and } \\
\text { Resiliency: An Evaluation of } 87 \text { Local Recovery } \\
\text { Plans in Eight States." }\end{array}$ & $\begin{array}{l}\text { Journal of the } \\
\text { American Planning } \\
\text { Association }\end{array}$ \\
\hline $\begin{array}{l}\text { Berke, P.R., and D. } \\
\text { Godschalk }\end{array}$ & 2009 & $\begin{array}{l}\text { "Searching for the Good Plan: A Meta-Analysis } \\
\text { of Plan Quality Studies." }\end{array}$ & $\begin{array}{l}\text { Journal of Planning } \\
\text { Literature }\end{array}$ \\
\hline $\begin{array}{l}\text { Berke, P.R., W. Lyles, and } \\
\text { G. Smith }\end{array}$ & 2014 & $\begin{array}{l}\text { "Impacts of Federal and State Hazard Mitigation } \\
\text { Policies on Local Land Use Policy." }\end{array}$ & $\begin{array}{l}\text { Journal of Planning } \\
\text { Education and } \\
\text { Research }\end{array}$ \\
\hline $\begin{array}{l}\text { Berke, P.R., G. Smith, and } \\
\text { W. Lyles }\end{array}$ & 2012 & $\begin{array}{l}\text { "Planning for Resiliency: Evaluation of State } \\
\text { Hazard Mitigation Plans under the Disaster } \\
\text { Mitigation Act." }\end{array}$ & $\begin{array}{l}\text { Natural Hazards } \\
\text { Review }\end{array}$ \\
\hline $\begin{array}{l}\text { Birkmann, J., and K. von } \\
\text { Teichman }\end{array}$ & 2010 & $\begin{array}{l}\text { "Integrating Disaster Risk Reduction and } \\
\text { Climate Change Adaptation: Key Challenges- } \\
\text { Scales, Knowledge, and Norms." }\end{array}$ & $\begin{array}{l}\text { Sustainability } \\
\text { Science }\end{array}$ \\
\hline $\begin{array}{l}\text { Feinberg, D.S., and C.M. } \\
\text { Ryan }\end{array}$ & 2020 & $\begin{array}{l}\text { "Evaluating the Quality and Implementation of } \\
\text { Hazard Mitigation Plans in Coastal Washington } \\
\text { State." }\end{array}$ & $\begin{array}{l}\text { Natural Hazards } \\
\text { Review }\end{array}$ \\
\hline $\begin{array}{l}\text { Hu, Q., Z. H. Tang, L. } \\
\text { Zhang, Y. Y. Xu, X. L. } \\
\text { Wu, and L. G. Zhang }\end{array}$ & 2018 & $\begin{array}{l}\text { "Evaluating Climate Change Adaptation Efforts } \\
\text { on the US } 50 \text { States' }\end{array}$ & Natural Hazards \\
\hline $\begin{array}{l}\text { Lyles, W., P. Berke, and G. } \\
\text { Smith }\end{array}$ & 2014 & $\begin{array}{l}\text { "A Comparison of Local Hazard Mitigation Plan } \\
\text { Quality in Six States, USA." }\end{array}$ & $\begin{array}{l}\text { Landscape and Urban } \\
\text { Planning }\end{array}$ \\
\hline $\begin{array}{l}\text { Preston, B.L., R.M. } \\
\text { Westaway, and E.J. Yuen }\end{array}$ & 2011 & $\begin{array}{l}\text { "Climate Adaptation Planning in Practice: An } \\
\text { Evaluation of Adaptation Plans from Three } \\
\text { Developed Nations." }\end{array}$ & $\begin{array}{l}\text { Mitigation and } \\
\text { Adaptation Strategies } \\
\text { for Global Change }\end{array}$ \\
\hline $\begin{array}{l}\text { Schrock, G., E.M. Bassett, } \\
\text { and J. Green }\end{array}$ & 2015 & $\begin{array}{l}\text { "Pursuing Equity and Justice in a Changing } \\
\text { Climate: Assessing Equity in Local Climate and } \\
\text { Sustainability Plans in U.S. Cities." }\end{array}$ & $\begin{array}{l}\text { Journal of Planning } \\
\text { Education and } \\
\text { Research }\end{array}$ \\
\hline $\begin{array}{l}\text { Stults, M., and S. C. } \\
\text { Woodruff }\end{array}$ & 2017 & $\begin{array}{l}\text { "Looking under the Hood of Local Adaptation } \\
\text { Plans: Shedding Light on the Actions Prioritized } \\
\text { to Build Local Resilience to Climate Change." }\end{array}$ & $\begin{array}{l}\text { Mitigation and } \\
\text { Adaptation Strategies } \\
\text { for Global Change }\end{array}$ \\
\hline $\begin{array}{l}\text { Woodruff, S. C., and M. } \\
\text { Stults }\end{array}$ & 2016 & $\begin{array}{l}\text { "Numerous Strategies but Limited } \\
\text { Implementation Guidance in US Local } \\
\text { Adaptation Plans." }\end{array}$ & $\begin{array}{l}\text { Nature Climate } \\
\text { Change }\end{array}$ \\
\hline
\end{tabular}




\begin{tabular}{|c|c|c|c|}
\hline Author(s) & Year & Title & $\begin{array}{l}\text { Journal or } \\
\text { Publisher }\end{array}$ \\
\hline $\begin{array}{l}\text { Woodruff, S.C., S. } \\
\text { Meerow, M. Stults, and C. } \\
\text { Wilkins }\end{array}$ & 2018 & $\begin{array}{l}\text { "Adaptation to Resilience Planning: Alternative } \\
\text { Pathways to Prepare for Climate Change." }\end{array}$ & $\begin{array}{l}\text { Journal of Planning } \\
\text { Education and } \\
\text { Research }\end{array}$ \\
\hline & & Terminology concept examinations & \\
\hline $\begin{array}{l}\text { Davidson, J. L., C. } \\
\text { Jacobson, A. Lyth, A. } \\
\text { Dedekorkut-Howes, C. L. } \\
\text { Baldwin, J. C., et al. }\end{array}$ & 2016 & $\begin{array}{l}\text { "Interrogating Resilience: Toward a Typology to } \\
\text { Improve Its Operationalization." }\end{array}$ & Ecology and Society \\
\hline $\begin{array}{l}\text { Folke, C., S.R. Carpenter, } \\
\text { B..Walker, M. Scheffer, T. } \\
\text { Chapin, and J. Rockstrom }\end{array}$ & 2010 & $\begin{array}{l}\text { "Resilience Thinking: Integrating Resilience, } \\
\text { Adaptability and Transformability." }\end{array}$ & Ecology and Society \\
\hline $\begin{array}{l}\text { Lei, Y., J. Wang, Y. Yue, } \\
\text { H. Zhou, and W. Yin }\end{array}$ & 2014 & $\begin{array}{l}\text { "Rethinking the Relationships of Vulnerability, } \\
\text { Resilience, and Adaptation from a Disaster Risk } \\
\text { Perspective." }\end{array}$ & Natural Hazards \\
\hline $\begin{array}{l}\text { Meerow, S., and J. P. } \\
\text { Newell }\end{array}$ & 2015 & $\begin{array}{l}\text { "Resilience and Complexity A Bibliometric } \\
\text { Review and Prospects for Industrial Ecology." }\end{array}$ & $\begin{array}{l}\text { Journal of Industrial } \\
\text { Ecology }\end{array}$ \\
\hline $\begin{array}{l}\text { Meerow, S., J. P. Newell, } \\
\text { and M. Stults }\end{array}$ & 2016 & "Defining Urban Resilience: A Review." & $\begin{array}{l}\text { Landscape and Urban } \\
\text { Planning }\end{array}$ \\
\hline Meerow, S., and M. Stults & 2016 & $\begin{array}{l}\text { "Comparing Conceptualizations of Urban } \\
\text { Climate Resilience in Theory and Practice." }\end{array}$ & Sustainability \\
\hline $\begin{array}{l}\text { Moser, S., S. Meerow, J. } \\
\text { Arnott, and E. Jack-Scott }\end{array}$ & 2019 & $\begin{array}{l}\text { "Comparing Conceptualizations of Urban } \\
\text { Climate Resilience in Theory and Practice." }\end{array}$ & Climatic Change \\
\hline $\begin{array}{l}\text { Romero-Lankao, P., D. M. } \\
\text { Gnatz, O. Wilhelmi, and } \\
\text { M. Hayden }\end{array}$ & 2016 & $\begin{array}{l}\text { "Urban Sustainability and Resilience: From } \\
\text { Theory to Practice." }\end{array}$ & Sustainability \\
\hline $\begin{array}{l}\text { Wied, M., J. Oehmen, and } \\
\text { T. Welo }\end{array}$ & 2020 & $\begin{array}{l}\text { "Conceptualizing Resilience in Engineering } \\
\text { Systems: An Analysis of the Literature." }\end{array}$ & Systems Engineering \\
\hline \multicolumn{4}{|c|}{ State of practice, implementation, or research examinations } \\
\hline $\begin{array}{l}\text { Bierbaum, R., J. B. Smith, } \\
\text { A. Lee, M. Blair, L. Carter, } \\
\text { et al. }\end{array}$ & 2013 & $\begin{array}{l}\text { "A Comprehensive Review of Climate } \\
\text { Adaptation in the United States: More than } \\
\text { before, but Less than Needed." }\end{array}$ & $\begin{array}{l}\text { Mitigation and } \\
\text { Adaptation Strategies } \\
\text { for Global Change }\end{array}$ \\
\hline $\begin{array}{l}\text { Koliou, M., J.W. van de } \\
\text { Lindt, T.P. McAllister, } \\
\text { B.R. Ellingwood, M. } \\
\text { Dillard, and H. Cutler }\end{array}$ & 2020 & $\begin{array}{l}\text { "State of the Research in Community } \\
\text { Resilience: Progress and Challenges." }\end{array}$ & $\begin{array}{l}\text { Sustainable and } \\
\text { Resilient } \\
\text { Infrastructure }\end{array}$ \\
\hline $\begin{array}{l}\text { B. Perkins, D. Ojima, and } \\
\text { R. Corell }\end{array}$ & 2007 & $\begin{array}{l}\text { "A Survey of Climate Change Adaptation } \\
\text { Planning." }\end{array}$ & Heinz Center \\
\hline $\begin{array}{l}\text { Sellberg, M., C. } \\
\text { Wilkinson, and G.D. } \\
\text { Peterson }\end{array}$ & 2015 & $\begin{array}{l}\text { "Resilience Assessment: A Useful Approach to } \\
\text { Navigate Urban Sustainability Challenges." }\end{array}$ & Ecology and Society \\
\hline
\end{tabular}




\section{Annotated Bibliography}

Each article below is summarized by a statement about the article purpose, the methodology presented in the article (including sample selection approach), a summary of the results and conclusion, and if applicable, a description of a typology of plan evaluation or RAS related planning concepts that could inform the development of a future analytical methodology.

\subsection{Plan Evaluation Studies and Methodology Examinations}

1. Baker, Ingrid, Ann Peterson, Gregory Brown, and Clive Mcalpine. "Local Government Response to the Impacts of Climate Change: An Evaluation of Local Climate Adaptation Plans." Landscape and Urban Planning 107 (August 1, 2012): 127-136. https://doi.org/10.1016/j.landurbplan.2012.05.009.

Article Purpose: There is an ever-growing need for local jurisdictions to devise measures to be ready for, and adapt to, climate change, thus promoting the importance of climate change adaptation (CCA) planning. This study evaluated the effectiveness and plan quality of local jurisdictions in Australia's CCA plans. This study also identifies limitations of current planning procedures.

Methodology: The authors conducted a census of local climate plans through searching Australian local government websites or national government websites to identify local governments that had received grants to conduct local climate risk assessment and action planning. This resulted in a sample of seven local adaptation plans for single jurisdictions and two plans that were developed by regional organizations. Plans were evaluated based on predetermined statements reflecting ideal outcomes. The outcome criteria were different categories that the ideal outcome needed to address. Overall progress and plan quality were measured using plan components and a system of enumeration ( 0 to 4, 0 meaning no evidence and 4 meaning full, detailed description). The received scores were cross checked by other members of the research team to assess intercoder reliability. All plans were compared against a respective total score to see how well they met the established requirements. Interviews were then conducted with government representatives to gain their view on their plan's score.

\section{Typology of topics used in review of literature/plans/documents:}

\section{Outcome Criteria}

1. Water Resource Planning

a. Water quantity is maintained or improved

b. Water quality is maintained or improved

c. Impacts of flooding are minimized or avoided

2. Environmental Planning and Biodiversity Conservation

a. Landscape structure, composition and function are maintained

b. Ecosystem, species and genetic diversity is maintained

3. Urban Planning

a. Urban heat island effects are minimized or avoided 


\section{Coastal Management}

a. Impacts of sea level rise and storm surge are minimized

5. Fire Management

a. Wildlife risks are managed and impacts are minimized or avoided

$\underline{\text { Plan Components }}$

1. Information base

2. Vision, goals and objectives

3. Options and priorities

4. Actions

5. Implementation and monitoring

Results and Conclusions: Each local government was measured based on their awareness, analysis, and action of climate change adaptation. Overall, local governments scored very well on the awareness element receiving an aggregate $62 \%$ of total scores. Conversely, for analysis and action, no criteria received above half the total. It was related to adaptation plans that provided only limited descriptions of outcome criteria.

This study identified limitations of plans in many aspects. The most significant limitations seen in plans was the failure to consider climate change adaptation across all levels and sectors.

Climate change has been historically considered an environmental problem. However, more recently it has become a multi sectoral issue. This study revealed a significant disparity between the thoroughness of plans when compared to each other. To address this gap, the article suggests that local governments should be provided with specific targets/goals that are required to be met instead of a generalized framework. Contextually, the apparent lack of pertinent scientific data to guide local planning greatly affected plan quality. This study strongly encourages implementation of vulnerability and risk assessments with hazard data.

2. Berke, Philip R., and Maria Manta Conroy. "Are We Planning for Sustainable Development?" Journal of the American Planning Association 66, no. 1 (March 31, 2000): 21-33. https://doi.org/10.1080/01944360008976081.

Article Purpose: This article presents and uses six identified principles that describe elements of sustainable development. Using these principles, a framework was developed and a sample of 30 comprehensive plans were evaluated to determine how well their policies support sustainable development.

Methodology: The study initially identified a sample of local plans that were placed into two groups: (1) those that identified sustainable development as an organizing concept, and (2) those that were noted as high quality plans but did not identify sustainable development as an organizing concept. Sustainable development principles and policies were created and the resulting plans were evaluated based on this plan evaluation protocol. The mean, and total scores for each plan was calculated, for each principle. 


\section{Typology of topics used in review of literature/plans/documents:}

Sustainable Development Principles

1. Harmony with Nature

2. Livable Built Environment

3. Place Based Economy

4. Equity

5. Polluters Pay

6. Responsible Regionalism

Results and Conclusions: The study's findings indicate that highest scoring plans combine various policies from all sustainable development principles to create a holistic plan. Although plans were observed to be diverse in terms of the total scores received, no trend for sustainable development was observed. For example, Jacksonville, FL scored highest although no outright mention was made of sustainable development as a planning concept.

A deeper assessment was conducted, comparing scores for both sample groups with sustainability principles. The results revealed that plans' performance was independent of the inclusion of sustainable development concepts. The authors noted that code words for sustainability are not present in dialogue within many communities, however sustainability principles and outcomes are accepted.

Some sustainability principles occur more frequently than others. Most plans addressed elements of the built environment, while other principles received less attention. Principles such as "polluters pay" and "responsible regionalism" received exceptionally low scores. This is observed to be related to the lack of regional governance jurisdictions for this type of planning. Other approaches discussed to improve the prevalence of sustainability principles include the use of disincentives (e.g., pollution taxes, permits).

Merely including sustainability within a plan was observed to have no effect on how well the plans actually incorporates the concept in respective governments' plans. Sustainable planning is still relatively new, and planners may only have a narrow understanding of how to apply the concepts. Plans do not thoroughly integrate sustainable development principles, but instead focus on specific sections. Increasing planners capacity to understand how to use sustainability principles would in part address this shortcoming. 
3. Berke, Philip, John Cooper, Meghan Aminto, Shannon Grabich, and Jennifer Horney. "Adaptive Planning for Disaster Recovery and Resiliency: An Evaluation of 87 Local Recovery Plans in Eight States." Journal of the American Planning Association 80, no. 4 (October 2, 2014): 310-23. https://doi.org/10.1080/01944363.2014.976585.

Article Purpose: Plan quality evaluation of disaster recovery planning has received considerably less attention than more conventional planning. The article evaluates local disaster recovery planning within eight coastal states. The authors achieve this by presenting a framework and conducting modelling that was used to evaluate how well the plans met the plan quality principles, as well as suggest reasons for their findings.

Methodology: The sample for this study were all coastal counties and municipalities located within eight states between Virginia and Louisiana. A coding instrument, utilizing a discrete binary scale and using predetermined indicators, was developed to assess how well the plans addressed the preassigned plan quality principles and an index score was computed for each of the plan principles. Multivariate analyses were used to evaluate proposed ideal variations of plan outcomes.

\section{Typology of topics used in review of literature/plans/documents:}

Definitions and Indicators of Plan Quality Principles

Direction Setting Principles

1. Goals

2. Fact Base

3. Policies

Action Oriented Principles

1. Inter organizational Coordination

2. Participation

3. Implementation and Monitoring

Plan Design Options

1. Stand-alone communitywide recovery plan

2. Comprehensive land use plan

3. Emergency management plan

4. Small area recovery plan

Results and Conclusions: It was observed that plans were seen to offer weak support for long term resiliency. No principle received more than half of the maximum possible score. The plan quality results of this study imply that local authorities have historically not demonstrated a strong commitment for disaster recovery planning through their recovery plans. 
Disaster recovery is generally new within most local jurisdictions; this study argues that a major hindrance is the fact that unlike other matters, disaster recovery does not have an established network of participating stakeholders. Only after the fact of a crisis does it seem like an area of importance. Although having involved stakeholders does generally help planning, the authors projected that a standalone community plan would have the most positive impact on disaster recovery planning initially. This plan allows local jurisdictions to work with a core group of collaborators toward common goals. The article suggests that meeting initial recovery targets is important to foster capacity for long term, collaborative recovery planning.

Further research is needed on the effectiveness of disaster recovery plans in practice. Relatedly, the article suggests that utilizing interorganizational networks for collaborative recovery planning is key to successful planning, and that future research should focus on the effects of collaboration on plan quality and implementation.

4. Berke, Philip, and David Godschalk. "Searching for the Good Plan: A Meta-Analysis of Plan Quality Studies.” Journal of Planning Literature, February 1, 2009. https://doi.org/10.1177/0885412208327014.

Article Purpose: The article describes a meta-analysis of comprehensive plan qualities studies to describe the emergence of an evaluative methodology to examine community plans. The article presents a plan quality evaluation methodology, with a discussion of the dimensions, principles, and criteria constituting the method's elements.

Methodology: A content analysis was performed on 16 plan quality studies across topics, including hazards, sustainable development, human rights, ecosystems, smart growth, housing affordability, watershed, and coastal issues. This sample was developed through a search of peer reviewed articles in the Journal of Planning Literature between 1995 to 2008 that included mean or proportional scores for plan quality findings and reported number of plans evaluated. A qualitative review, based in part on plan quality characteristics presented in Berke, Godschalk and Kaiser 2006, identified 7 internal plan quality characteristics and 3 external plan quality characteristics that were present in each of the studies examined. Utilizing these characteristics, a discrete binary scale was used to transform the characteristic scores described in each of the studies to a proportional score.

\section{Typology of topics used in review of literature/plans/documents:}

\section{Characteristics of Plan Quality (Adapted from article Table 2)}

Internal characteristics (internal to plan document)

1. Issue identification and vision: community needs, future vision, major issues, forecasted change

2. Goals: reflections of public values for future land use and development

3. Fact base: analytical basis for current and future conditions 
4. Policies: principles to guide public and private land use decisions, specific statements for infrastructure planning and design

5. Implementation: commitment to carry out plan actions, timelines, budgets

6. Monitoring and evaluation: metrics for tracking, measurable objectives, responsible organizations and individuals

7. Internal consistency: elements of plan are reinforcing and consistent

External characteristics (external to plan document and development process)

1. Organization and presentation: accessibility to readers and stakeholders, contains visualizations

2. Interorganizational coordination: integrates with other plans or policies, addresses other organizations or jurisdictions plans where relevant

3. Compliance: inclusion of all required elements

Results and Conclusions: For the internal characteristics, the meta-analysis found that plan quality scores ranged from 0.25 to 0.63 , representing a wide variability in how well plans define issues. The authors inferred that the types of studies that scored low often lacked a comprehensive stakeholder engagement process, which later can lead to policy solutions that may not be well suited to address the ill-defined issues in the plans. Breaking down this range further, goals, fact base, and policy categories represented the lowest scoring categories, which indicate issues with plans articulating narrowly scope goals and the associated actions that would address them. The exceptions to this goal, fact base, and policy finding relate to plans where there are strong directive frameworks in place, such as state mandated coastal plans in North Carolina where local issues related to protecting natural ecosystems and coastal economic development are prevalent and drive planning efforts. For external characteristics, plans rate relatively highly for compliance indicating that plans often go above minimum requirements.

In addition to presenting the results of the plan quality evaluation meta-analysis, the article reviews the methodologies utilized in the studies analyzed. From this examination, the article describes elements of a uniform plan quality evaluation instrument (based upon the elements described above). This qualitative content analysis approach recommends intercoder reliability practices and agreement levels described in Krippendorf 2004, including use of multiple independent coders, consistent and appropriate intercoder agreement technique, and an acceptable level of agreement (based on intercoder reliability score).

5. Berke, Philip R., Ward Lyles, and Gavin Smith. "Impacts of Federal and State Hazard Mitigation Policies on Local Land Use Policy:" Journal of Planning Education and Research, January 16, 2014. https://doi.org/10.1177/0739456X13517004.

Article Purpose: The article presents an examination of the impacts of FEMA's Community Rating System (CRS) and the Disaster Mitigation Act (DMA), namely the requirement to develop a hazard mitigation plan, on local community's use of land use planning policy to 
achieve disaster mitigation objectives. The analysis utilizes a sample of hazard mitigation plans prepared in North Carolina and Florida to examine the independent effects of federal policy on the use of local land use policy actions.

Methodology: Two samples of DMA plans from Florida and North Carolina communities were collected, which covered coastal communities, non-coastal communities, and community plans that were submitted under the CRS. Communities with populations greater than 5,000 were considered and several major metropolitan areas (e.g., Miami) were excluded due to their much greater planning complexity. The plans were qualitatively coded using plan quality variables, local contextual variables, and variables that represent the presence of federal and state planning programs and mandates. Poisson regressions were used to test for differences in various preventative measures in response to the presence or absence of federal measures. Interviews with the state hazard mitigation planning officials were also conducted to understand the extent to which states were devolving authority to communities to develop mitigation plans, availability of technical assistance, participatory planning, and funding support.

\section{Typology of topics used in review of literature/plans/documents:}

\section{Plan quality evaluation variables (presented in article Table 2. Sources and Measurement of} $\underline{\text { Variables) }}$

1. Plan Quality Variables

a. Preventative actions

b. Structural protection of property actions

c. Emergency services actions

d. Information and awareness actions

e. Structural protection of infrastructure actions

2. Federal and State Variables

a. Community rating system

b. Located in North Carolina or Florida

3. Community Variables
a. Population,
b. Population growth
c. Median home value
d. Disaster frequency
e. Planner holding a seat on planning community

Results and Conclusions: Differences between Florida and North Carolina were observed in how state policy influences mitigation planning. The State of Florida utilizes a top-down approach to guide mitigation planning through a high level of technical support, guidance on the use of cost-benefit analysis decision support and other state level prioritization criteria that are promulgated by the Florida Department of Community Affairs. The State of North Carolina gives local governments more authority over their planning process and the solutions presented within them. To support these efforts, the State of North Carolina provides an incentive through 
providing the matching funds required by federal programs. Both states provide local governments dedicated funding support for hazard mitigation planning activities.

Across the plan quality variables examined, preventative land use policies were observed the least compared to the other policies. The most prominent type of policy was emergency services, while the other three action categories were not observed to be statistically different from the aforementioned preventative land use and emergency services categories. Between the two states, the analysis found that land use measures were observed more often in North Carolina than Florida, such as subdivision design codes (+73\% greater in NC than FL), zoning (49\%), hazard area setbacks $(38 \%)$. This indicates that state level program and policy design has an influence on the use of land use policies. Additionally, the state level analysis found that strong state level policy can have a greater influence on including land use actions than local contextual factors and when state level incentives are not present, an equal level of influence can be achieved through strong local planning department involvement and leadership.

The analysis found that the federal DMA and CRS programs did not affect observed differences between how plans represented and used land use measures. For CRS, one potential explanation is that the credit system does not provide adequate crediting or weighting to influence a change in policy. Specifically, CRS only provides up to 294 credits for land use measures out of a total 4,500 available credits and premium reductions are only provided when a community satisfies increments of 450 credits. From these results, the authors provide several recommendations for policy action to improve how communities incorporate land use policy within hazard mitigation plans. For federal programs, stronger requirements for the use of preventative land use measures, deemphasizing the use of emergency services as mitigation measures, financial incentives, and increased weighting of CRS land use measures would enhance land use policy as a mitigation measure. Other approaches could involve federal program support for the involvement and mitigation training of local planners, but without mandating requirements.

6. Berke, P., G. Smith, and W. Lyles. "Planning for Resiliency: Evaluation of State Hazard Mitigation Plans under the Disaster Mitigation Act." Natural Hazards Review 13, no. 2 (May 2012): 139-49. https://doi.org/10.1061/(asce)nh.1527-6996.0000063.

Article Purpose: State Hazard Mitigation Plans (SHMPs) hold a very vital purpose in supporting disaster mitigation and resilience. Based on six principles of plan quality closely aligned with the Disaster Mitigation Act (DMA), and through the use of a qualitative coding instrument, this article analyzes a sample of coastal SHMPs to determine how well they support hazard mitigation objectives.

Methodology: The sampling unit for this study was SHMPs. Thirty coastal SHMPs were selected because of their diversified geographic locations and range of population growth rates. A coding instrument was developed to quantitatively analyze each plan, based on 6 main principles (listed below). The study utilized both a discrete binary ( 0 to 1 to indicate presence) 
and discrete ordinal ( 0 to 2 with 2 being clear and detailed description) scale to describe the inclusion of a plan element. Descriptive statistics (mean, standard deviation, and range) for each plan principle and element across SHMPs were then compared.

\section{Typology of topics used in review of literature/plans/documents:}

List of Principles, Indexes, and Items for Plan Coding

1. Goals
a. Hazard Loss
b. State and Local Coordination
c. Overarching Vision:

2. Fact Base
a. Quality of Hazard Assessment
b. Hazards Addressed and Their Prioritization
c. Vulnerability Assessment
d. Risk Assessment
e. Capability Assessment

3. Mitigation Policies
a. Promotion of Awareness/Knowledge
b. Development Regulations
c. Development Incentives
d. Acquisition
e. Structural Controls
f. Protection of Public Facilities and Infrastructure
g. Recovery Measures
h. Financial Assistance

4. Implementation and Monitoring
a. Evaluation and Update
b. Monitoring Implementation
c. Implementation Support

5. Interorganizational Coordination

a. State Review of Local Plans

b. State Priorities for Assisting Local Government

c. State Provision of Support for Local Governments

6. Participation
a. Process of Developing and Updating Plan
b. Organizational Involvement
c. Public Engagement

Results and Conclusions: In order to display a measure of how committed the selected states were to promoting hazard mitigation, the mean scores for both internal and external principles 
were computed for their respective HMPs. Generally, the plans scored relatively low in all principles. The highest mean for the internal and external principles were 0.97 and 0.87 respectively, out of a maximum score of 2 . These scores indicate that states failed to assemble high quality hazard mitigation plans based on their scoring criteria.

The highest scoring internal principle was goals. Under this principle, plans typically placed importance on the reduction of hazard loss (mean $=1.21)$ but the least priority was seen on incorporating mitigation concepts to resiliency and sustainability (mean $=0.23$ ). These scores highlight that the plans only place importance on lower effort mitigation solutions. On a deeper level however, mitigation combats loss reduction due to hazards while also advancing resilience or ability to bounce back from the impacts. Fact base was second highest with a mean of 0.90 . The depth of the hazard assessment conducted scored high (mean $=1.44$ ) with risk and vulnerability assessments also scoring high (mean $=1.05$ and 1.17 , respectively). All other indices scored low alluding that states lacked sufficient data and knowledge on prioritizing hazards and their risks. Policies scored low with an overall mean of 0.60 , although states did agree that having considerable variation of policy types had positive impacts. Implementation and monitoring received a low overall mean of 0.85 . With both external principles, interorganizational coordination and participation scoring low (mean $=0.87$ and 0.65 respectively), the results are ultimately moderate to low. However, when they were compared with a similar study conducted in the 1990s conducted by Godschalk et al. (1998), plans showed significant improvements, particularly with the inclusion of many key sections in all principles.

The DMA only encourages a minimal level of requirements to receive funding and it is likely that this did not create an incentive to produce higher quality plans. California produced the only plan that was above average for all principles. From state to state, disasters vary greatly, influencing the disparities in plan quality. In order to improve plan quality, states need to address the work of emergency management alongside other aspects of sustainability such as environmental preservation and water quality. In addition to this, plans must be held accountable to a higher standard and be subject to continuous updating every planning cycle.

7. Birkmann, Jörn, and Korinna von Teichman. "Integrating Disaster Risk Reduction and Climate Change Adaptation: Key Challenges-Scales, Knowledge, and Norms." Sustainability Science 5, no. 2 (July 1, 2010): 171-84. https://doi.org/10.1007/s11625010-0108-y.

Article Purpose: The article explores systematic linkages between disaster risk reduction planning (DRR) and climate change adaptation (CCA) concepts in theory and practice. In practice there have been differences in focus, scale, and objectives that have hindered the integration of these concepts. The authors hypothesize that the differences and challenges between DRR and CCA can be categorized into differences related to spatial and temporal scales of planning and analysis, differing knowledge bases, and norms. 
Methodology: The authors conduct a literature review of national level and local level adaptation strategies. National level plans include the National Adaptation Program of Action (NAPAs) and Strategic National Action Plans (SNAPs) related to the Hyogo Framework for Action. Structured and semi structured interviews (38 total) were conducted between April and May 2009 with subject matter experts in humanitarian organizations, governmental agencies and ministries, international philanthropic and scientific organizations, development organizations, public DRR organizations, and climate science experts. The interviews focused on identifying existing barriers to linking DRR and CCA.

\section{Typology of topics used in review of literature/plans/documents:}

Definitions (Multiple presented in the article, summary definitions provided below):

1. Vulnerability: From a natural hazards perspective, exposure conditions that make people and places vulnerable to extreme natural events, societal resistance of resilience to hazards, and integration of exposures and societal resilience with a specific on particular regions. (Cutter et al 2003, Kasperson and Kasperson 2001, Cutter and Finch 2008)

2. Resilience: From a natural hazards perspective, broadly defined as the capacity to resist and recovery from disaster losses (Zhou et al. 2010).

3. Adaptation: The process, action, or ability of an individual or system to improve inherent characteristics to accommodate change, such as through social learning. This includes moderating harm and exploiting beneficial opportunities.

Results and Conclusions: The authors find that the current status of DRR and CCA integration are limited and often are presented at a conceptual level. This is observed most often in national level guidance (e.g., German Adaptation Strategy to Climate Change (2008), UK Climate Impacts Program (UKCIP 2009)). These programs suggest that there are two prominent approaches: (1) tool development that provides sector specific guidance and program level tools to integrate scientific information on climate change exposure, and (2) guidance on adaptation and prevention measures.

Despite these areas of integration, three major categories of challenges that hinder integration: differences in spatial and temporal scales of planning, differing knowledge bases, and differing norms between DRR and CCA planning. Scale mismatches relate to spatial scale differences in CCA where analytical results have focused on global scale impacts (e.g., changes in average temperature), while DRR has focused on regional or local scale has been the focus of the DRR community, specifically on local vulnerabilities and risk due to specific hazards. Temporal scale differences relate to DRR's focus on sustainable development objectives, while CCA strategies and planning processes focus on long term perspectives that are greater in duration than most political timescales. The temporal scale differences relate to funding streams, where DRR aligns with philanthropic and shorter-term funding, while CCA objectives require longer term financial support. 
At the governmental level, DRR has been observed (as of 2010) to lie within agencies responsible for civil emergencies agencies, while CCA is the domain of agencies with responsibilities for environmental protection. Knowledge mismatches refer to the lack of norms, indicators, and standards that would support objective integration of DRR and CCA. This includes differences in terms and definitions (or lack thereof) and common data and information sources. A major difference between the two approaches is the use and reliance on scientific and local/traditional knowledge, where both rely on local priorities, knowledge, and experiences to confirm or incorporate scientific findings. Norm mismatches refer to legislative, cultural, or behavioral norms, which may be implemented in practice by differing approaches. For example, CCA has been traditionally implemented through environmental programs that have focused on greenhouse gas mitigation and transitioned to considering how to address the effects of climate change, while DRR may refer to concrete legal norms, such as coastal laws or zoning regulations.

8. Feinberg, Daniel S., and Clare M. Ryan. "Evaluating the Quality and Implementation of Hazard Mitigation Plans in Coastal Washington State.” Natural Hazards Review 21, no. 2 (May 1, 2020): 04020013. https://doi.org/10.1061/(ASCE)NH.1527-6996.0000372.

Article Purpose: The article's overall objective was to determine what components of highquality plans are present in the selected hazard mitigation plans. Collaboration within planning processes are examined by surveying hazard planning professionals. Dimensions of collaboration that the professionals deem important are noted. The authors explore the extent to which these collaboration dimensions were associated with high scoring plans.

Methodology: The sample for this study comprised of 19 counties in western Washington that were selected because they were very prone to several types of natural hazards. The plans were coded by one author (as opposed to utilizing a standard methodological approach of double coding, due to study limitations) and evaluated by the study authors based on an existing protocol developed by the Hazard Reduction and Recovery Center in 2008. The protocol contained 126 coding items organized within the seven plan quality principles. The items were scored on a 0 to 2 scale ( 0 being not mentioned and 2 being discussed in detail). The item scores within each principle were summed, divided by the total possible score, and multiplied by 10 to give a component score on a scale from 0 to 10. An online survey was conducted via email to 95 hazard planning professionals, and the results tabulated.

\section{Typology of topics used in review of literature/plans/documents:}

$\underline{\text { Plan Quality Principles }}$

1. Vision and Statement

2. Fact Basis

3. Planning Process

4. Mitigation Goals and Objectives 
5. Interorganizational coordination

6. Specific Mitigation Policies and Actions

7. Implementation

Dimensions of Collaboration

1. Governance

2. Administration

3. Autonomy

4. Mutuality

5. Norms

Results and Conclusions: The highest scoring elements of the plans were vision statements. Plans typically addressed their vision and scope very well, but did not address other components in such detail (e.g., goals, objectives, other tangible outcomes).

Based on the survey's results, planning professionals view their respective jurisdictions' planning process as collaborative. However, despite the planning professionals' views, their specific plan's results highlight a disparity between planning and implementation. Planners made mention of the fact that resource scarcity exists, and plans are being made to fit the current economic conditions.

Results also show that not all plan action items are being put into practice. Plan implementation lacked sufficient influences from areas such as funding, guidance, and collaboration. Although planners claimed the process is collaborative, this study highlights that more work is needed to foster sectoral relations in order to produce high quality plans.

9. Hu, Q., Z. H. Tang, L. Zhang, Y. Y. Xu, X. L. Wu, and L. G. Zhang. "Evaluating Climate Change Adaptation Efforts on the US 50 States' Hazard Mitigation Plans." Natural Hazards 92, no. 2 (June 2018): 783-804. https://doi.org/10.1007/s11069-018-3225-z.

Article Purpose: Climate change within government mitigation plans has never fully been investigated. This study examines how much states consider climate change within their state hazard mitigation plans (SHMPs). The authors analyze the SHMPs through the lens of 18 developed indicators that examine the extent to which climate change is considered across the sample.

Methodology: The sample for this study was the SHMPs corresponding to each state, with publication dates ranging from 2010 to 2015. A three-point coding protocol was developed to evaluate the quality of plans in the study. The protocol utilized the developed indicators and was graded on a discrete ordinal scale ( 0 to 2 ) with 0 being not included and 2 being thoroughly discussed. The plan quality was measured by summing together in each individual category then dividing by the theoretical full score of the category, indicating the "breadth" category. A 
"depth" category was also implemented to display how extensively the plans addressed a specific indicator.

\section{Typology of topics used in review of literature/plans/documents:}

\section{List of Resilience categories}

1. Awareness

2. Analysis

3. Action

Results and Conclusions: This study indicated that SHMPs had average to low levels of quality in all categories. Large discrepancies were observed within the 50 state plans. and only 7 states scored above 80 points out of a total of 100 . Most states that received high scores were coastal states. The authors attributed this to the fact that the coastal states encounter more hazards than the others do.

The discrepancies can be due to the fact that although there are frameworks in place such as FEMA's 2011 adaptation policy statement, direct requirements are still lacking and as a result, planners do not have clear goals to meet. Planners are not necessarily equipped with a large volume of available knowledge and as a result, risk and vulnerability assessments of different types of hazards are not often seen. This results in inefficient allocation of time and resources.

Communities should promote integrating climate change experts into their planning teams. This must be done to foster climate change relations within the field of hazard mitigation. In addition to this, resiliency must also be merged into the current planning process. Current measures being implemented are more focused on keeping the current status quo instead of using it as a baseline and projecting higher. Communities are lacking in climate change education and awareness. Climate change, as well as some other concepts such as resilience, is generally new and not fully understood. This means that the current plans seen in jurisdictions must be subject to reviews and updates in order to closer link the theory to practice.

SHMPs generally treat climate change with wide variation, with average plan qualities being observed throughout. The authors indicate that research such as this is necessary for climate change adaptation to take place because it gives more insight into whether or not jurisdictions' plans and measures are working. However, this study only focuses on theoretical planning documents, but studies must also be done on these documents in practice to further assess their quality. 


\section{Lyles, W., P. Berke, and G. Smith. "A Comparison of Local Hazard Mitigation Plan Quality in Six States, USA." Landscape and Urban Planning 122 (February 2014): 89- 99. https://doi.org/10.1016/j.landurbplan.2013.11.010.}

Article Purpose: State Hazard Mitigation Plans (SHMPs) play a significant role in natural hazard risk reduction. This article analyzes 6 coastal SHMPs based on 7 chosen principles of plan quality and local mitigation planning that are closely related to the Disaster Mitigation Act (DMA). The authors provide recommendations for how officials can target strategic adjustments to local mitigation planning.

Methodology: The article presents 175 selected coastal jurisdictions across 6 coastal states. A coding protocol, consisting of items selected based on FEMA's requirements for mitigation plans, was developed to evaluate the 7 principles of plan quality. The items were measured on a discrete binary scale to show presence or lack thereof of a quality or discrete ordinal ( 0 to 2 to show how detailed the item was with 2 being clear and detailed) scale. The content was analyzed by adding the scores for each of the items and dividing by the total possible score to obtain mean plan quality scores.

\section{Typology of topics used in review of literature/plans/documents:}

\section{Plan Quality Principles}

Direction setting principles

1. Goals

2. Fact Base

3. Policies

Action oriented principles

4. Participation

5. Interorganizational coordination

6. Implementation

7. Monitoring

Results and Conclusions: The highest mean score was observed for implementation (mean $=5.9$ ). Although the scores for both the direction setting and action-oriented principles were aggregately similar, a wide variation is observed between all states as local governments are not responding uniformly, in part because of DMA's flexible mandates. Plans lacked important areas such as goal specification. For example, plans valued protecting public safety and reducing damage, but goals related to resilience and sustainability were not common at all.

Over 26,000 local governments have adopted HMPs, showing that the DMA was successful in promoting the importance of having a HMP. However, states are not meeting their risk reduction goals. The inclusive framework of the DMA allows states the freedom to meet their required 
mandates to qualify for funding (i.e., does not provide an incentive structure) to take further action. The results of this study, low mean scores on all principles, reflect this dynamic.

Approaches to address this include the presentation of a firm framework and requirements, and coordination among national level organizations to provide examples of high-quality plans. Ultimately, responsibility for mitigation falls to states and local governments. Officials may need to consider extra encouragement and outreach with both higher level governance and the public, to encourage state level actions that should not just be dependent on external funding.

11. Preston, Benjamin L., Richard M. Westaway, and Emma J. Yuen. "Climate Adaptation Planning in Practice: An Evaluation of Adaptation Plans from Three Developed Nations. " Mitigation and Adaptation Strategies for Global Change 16, no. 4 (April 2011): 407-38. https://doi.org/10.1007/s11027-010-9270-x.

Article Purpose: The article presents a structured examination of climate adaptation plans across geopolitical scales. A description of the state of adaptation planning is provided, including descriptions of where gaps exist in terms of structure, process, or content. Additionally, an assessment the state of climate change preparedness based upon adaptation plan review is included.

Methodology: A qualitative analysis of 57 adaptation plans from Australia, the United Kingdom, and United States was conducted using Logical Framework Analysis methodology (LFA). Additionally, 20 adaptation planning guidance instruments were reviewed. These adaptation plans and guidance instruments cover various geopolitical scales (international to local). The LFA approach analyzes the relationships between programs and objectives, activities, inputs and resources to undertake those activities, and outputs. As part of developing the LFA methodology, an inductive approach was used to identify key steps in adaptation planning. Using the criteria described below, a 3 point discrete ordinal scale scoring criteria system to assess evidence for selecting an adaptation option was developed and used to evaluate options identified in the 57 adaptation plans (a total of 507 adaptation options identified within the 57 plans).

\section{Typology of topics used in review of literature/plans/documents:}

\section{Adaptation Planning Stages (Adapted from Table 2. Description of adaptation planning stages} and processes used as evaluation criteria in the current study.)

1. Goal setting: Establishing decision makers objectives for adaptation and specifying how performance will be measured or determined. Includes processes such as establishing objectives, goals, priorities, success criteria.

2. Stock taking: Assessing adaptive capacity of the institution, government, or organizations undertaking planning. This includes inventorying and assessing assets and liabilities related to 
adaptation planning and implementation. Includes assessments of human capital, social capital, natural capital, physical capital, and financial capital.

3. Decision making: Processes and steps for an organization to engage with stakeholders, assess preferences, assess impacts, vulnerabilities of adaptation priorities, and consideration for how to incorporate within existing policy structures and processes. Includes stakeholder engagement, assessment of climate and non-climate drivers, assessment of vulnerability and risk, uncertainty assessment, assessing options, consideration of mainstreaming.

4. Implementation and evaluation: Steps taken to implement chosen or preferred adaptation options, including communication, delegation of roles and responsibilities; also includes monitoring and evaluation of implementation activities. Includes communication, stakeholder outreach, defining roles and responsibilities, monitoring and evaluation.

Results and Conclusions: The results of the 57 adaptation plan review found that they are generally underdeveloped, which is indicated by the plans averaging only $37 \%$ of the total possible score (range was $16 \%$ to $61 \%$ ). There was an observed preference for lower risk capacity building solutions (e.g., creation of institutional frameworks for adaptation), compared to more specific actions (e.g., constructed solutions). The authors inferred this high frequency of institutional framework action represents a perception that organizations have a deficit of knowledge or lack the capacity to take actions. An analysis of the plan evaluation criteria indicated a strong association between actions; "implementation" and "evaluation, monitoring, and review"; "assessment of human capital" and "assessment of social capital"; "communication and outreach", "articulation of objectives, goals, and values", "implementation", "acknowledgment of assumptions and uncertainties".

The article presents an argument that, at the time of the article's publication, adaptation plans utilize a traditional impacts assessment approach (top-down) to acquire information about impacts and consequences. Management of those consequences is the end point of the assessment process, rather than a continuous process. Gaps were observed in plan discussion of incorporating the actions or priorities with other planning efforts (i.e., mainstreaming). Challenges such as the need for integration into other plans was attributed to the ad hoc nature of how the practice of adaptation planning was progressing as a practice and research topic. As a result, a lack of standardized planning guidance was observed. However, the authors noted that challenges exist with developing standardized planning guidance due to highly local and contextual nature of climate change impacts, vulnerability, and the types of policies and responses that are available. It was discussed that a response to this dynamic has been for the creation of more generalized planning frameworks in order to avoid over prescribing processes, actions, or outcomes, and to respect norms and cultures of various organizations undertaking adaptation planning efforts. 
12. Schrock, Greg, Ellen M. Bassett, and Jamaal Green. "Pursuing Equity and Justice in a Changing Climate: Assessing Equity in Local Climate and Sustainability Plans in U.S. Cities." Journal of Planning Education and Research 35, no. 3 (September 1, 2015): 282-95. https://doi.org/10.1177/0739456X15580022.

Article Purpose: The article presents the results of a qualitative analysis of 28 climate action plans and sustainability action plans published by mid and large sized US cities to examine how concepts of equity and justice are included in the plan development and content. The examination provides perspectives on how these issues are presented in comparison to other priorities, such as environmental or economic objectives.

Methodology: The authors reviewed 28 climate action plans and sustainability action plans from US cities. Large and mid-sized cities were a focus of the selection process due to the higher probability that plans produced by these cities were more likely to reflect issues oriented to their demographically, politically, and socioeconomic diverse populations. Using web searches, ICLEI-USA, and EPA collections of plans, 56 cities were identified and half were selected based on their representative characteristics of the top 100 cities. A qualitative coding scheme was used with a three point discrete ordinal scale to indicate how equity was represented in the plans, as described by the typology below.

\section{Typology of topics used in review of literature/plans/documents:}

Based on the work of Bullard (1994), three types of equity are considered in the qualitative analysis:

1. Procedural equity: fairness in public proceedings and decision making processes

2. Geographic equity: equity across neighborhoods, communities

3. Social equity: equity across race, ethnicity, and class

Results and Conclusions: Equity was not a prominent theme in the climate action plans and sustainability action plans reviewed (less than $50 \%$ ), although nearly all (90\%) included some discussion of the topic of equity. These discussions ranged from the topic as a goal, as a problem to be solved, or as a motivating factor for actions (e.g., assistance for lower income households). Social equity was the most prevalent type of equity mentioned in plans ( $33 \%$ of plans), while geographic equity second, and no plans making a prominent mention of procedural equity. Statistical analysis indicated there are no statistically significant relationships between the degree of inclusion of equity and city characteristics. For weaker statistical relationships, city size, poverty rate, and income inequity seem to be positively correlated with the inclusion of equity in the plans. The strongest relationships observed were the inclusion of equity in cities plans that were updates or revisions to prior plans. Cities where the plan reviewed was the only publication or first version received approximately $50 \%$ of the equity scores as those that were revisions or updates. The authors infer that this relationship may be due to increased capacity in city officials and relationships or the inclusion of pro-equity groups in shaping the agenda or scope of planning efforts. 
13. Stults, M., and S. C. Woodruff. "Looking under the Hood of Local Adaptation Plans: Shedding Light on the Actions Prioritized to Build Local Resilience to Climate Change." Mitigation and Adaptation Strategies for Global Change 22, no. 8 (December 2017): 1249-79. https://doi.org/10.1007/s11027-016-9725-9.

Article Purpose: Analyze the content of U.S. based local climate adaptation plans to identify actions proposed in the plans and compare the actions to those that would be recommended by research. The article characterizes and describes the gap between actions undertaken at the local level and scientific recommendations for action.

Methodology: The authors utilize plan content analysis methodologies presented in (Woodruff and Stults 2016), namely the plan quality principles, however in this study, only the actions principle (23 metrics utilized) and implementation and monitoring principles (16 metrics utilized) are examined. Plans published by U.S. local governments published between 2007 and 2014 were qualitatively coded and examined (43 plans total). The comparison actions in research literature were identified based upon the climate change impacts identified in the 2014 National Climate Assessment for the given region or location of the plan author community and utilized a qualitative literature review to determine adaptation actions recommended for the given region's climate change impacts.

\section{Typology of topics used in review of literature/plans/documents:}

Types of Adaptation Actions (Adapted from Table 2. The final 17 types of adaptation actions included in this analysis.)

1. Advocacy: encourage organization to take appropriate adaptation actions

2. Building codes and engineering design standards: improve physical infrastructure in response to changing climate conditions

3. Capacity building: developing human resources, institutional capacity, communities to adapt to changing conditions

4. Education and outreach: increasing public knowledge

5. Energy conservation: reducing energy consumption

6. Financing: financial incentives, budgeting to support adaptation

7. Funding: capital for adaptation activities

8. Green infrastructure: use of natural systems or processes for adaptation

9. Land use and zoning: processes or actions that determine how land will be used, where development will occur

10. Physical infrastructure: the creation, removal, or specification of how physical infrastructure is built

11. Planning: incorporating climate science, impacts, vulnerability, risk into government planning processes or initiatives

12. Policy: creation of new or revision of existing legislation of regulations

13. Practice and behavior: changing individual behavior, operations, management, or programs affecting resilience 
14. Research and monitoring: gathering information, reports, maps, models, or observations/measurements taken over time

15. Technology: development or use of technology solutions that reduce water use, produce renewable energy, enhance communications, hazard early warning systems

16. Water conservation: reducing water use

17. Greenhouse gas reduction: actions that reduce the emissions of greenhouse gases

Results and Conclusions: The review of the 43 local adaptation plans resulted in the identification of 3,375 discrete actions (mean 93 actions/plan, median 54 actions/plan). Most of the plans included 12 of the 17 types of adaptation actions, with several communities including 16 of the 17 types of actions. The most common type of action included was land use actions, which are composed of transfer of development rights or no-build policies. Advocacy, energy conservation, water conservation, and greenhouse gas mitigation actions were some of the least observed actions in the plans.

When compared to the recommendations that are found in research to address the localized climate change impacts, there was variation in how the actions compared and how the plans represented the hazards posed by climate change impacts. Generally, plans accurately identified and were well aligned with the types of climate change impacts identified in research literature. However, in coastal locations in particular, there was a significant focus on sea level rise while other relevant climate change impacts (e.g., increased in temperature, extreme heat, changing precipitation patterns) were less observed. Often plans organized actions into sector specific actions or strategies, or in some cases designated actions spatially based on neighborhood or population needs. While this type of organization is useful for implementation, monitoring, and evaluation, this organization poses challenges when attempting to attribute an action back to a specific hazard or climate impact.

An important observation from this study, compared to other prior plan evaluation studies, is that plans evaluated indicated a number of concrete actions to address hazards and climate change impacts, rather than solely low risk options such as capacity building. Overall, the adaptation plans examined rarely connected actions to specific climate change impacts, but they are including the types of actions that would address the impacts in their region. Some actions were less observed than would be expected, such as the use of enhanced building codes and green infrastructure in areas where increases in sea level rise, precipitation, wildfire, storm surge, and extreme wind as hazards that would be affected by climate change.

\section{Woodruff, S. C., and M. Stults. "Numerous Strategies but Limited Implementation Guidance in US Local Adaptation Plans." Nature Climate Change 6, no. 8 (August 2016): 796-+.https://doi.org/10.1038/nclimate3012.}

Article Purpose: Variability in the process, content, and implementation of climate change adaptation plans has been observed as communities across the United States develop plans to 
address the projected impacts of climate change. This article presents the results of a study of 44 local adaptation plans in the US, including the results of a multivariate regression to examine differences in plan quality and underlying rationale for why these differences are observed.

Methodology: Content analysis is used to examine 44 local adaptation plans, and multivariate regression is used to examine variability. A qualitative coding methodology is developed through an inductive examination of 9 adaptation guidance documents. The sample of local adaptation plans was developed through examination of the following adaptation clearinghouse websites: Georgetown Climate Center, CakeX, Center for Climate and Energy Solutions. Additionally, the authors conducted a structured Google search on the following terms: "local climate plan", "local adaptation plan", "local resilience plan", "local preparedness plan". This search collected three 100-page search results, resulting in 85 plans of which 44 were selected for review, based on those plans meeting the following criteria: central topic was adaptation, resilience, or preparedness; item by or for a US city or county government; presented the results of a comprehensive approach to adaptation (as opposed to a sector based approach).

\section{Typology of topics used in review of literature/plans/documents:}

Plan quality evaluation principles (Publication Table 1) based upon the work of Lyles and Stevens (2014) and Berke and Godschalk (2009):

1. Goals: Future desired conditions (plan purpose, vision, goals, and objectives)

2. Fact base: Empirical foundation that identifies and prioritizes issues to ensure that strategies are well informed (data sources, analysis of current conditions, climate change exposure, vulnerability, and risk assessment)

3. Strategies: Guide to decision making to ensure that plan goals are achieved (Capacity building, land use, green infrastructure, and other solutions; cost and co-benefits of options; prioritization of strategies)

4. Uncertainty: Recognition of and approaches to overcome uncertainty in future climate projections (recognize sources of uncertainty, consider future scenarios, robust or no regret strategies)

5. Public participation: Recognition of and strategies for engaging actors in preparing the plan (Description of planning processes and techniques to engage stakeholders, identification of individuals involved in plan preparation)

6. Coordination: Recognition of the interdependent actions of multiple organizations and the need for coordination (Engagement of local universities, state agencies, businesses, neighboring jurisdictions)

7. Implementation and monitoring: Guidance to translate plan strategies into action and track progress toward goals (Organizational responsibilities, timelines and funds for implementation and monitoring)

Results and Conclusions: Of the 44 local adaptation plans reviewed, across all of the plan quality evaluation principles and criteria utilized, the plans scored an average of $40.6 \%$ (with a range of $12 \%$ to $76.6 \%$ ) of available criteria, while only 12 plans scored above $50 \%$. Plans 
were observed to mostly frequently include elements of the strategies principle, with plans to use a variety of approaches to prepare for climate change, including changing community behavior and practices, and continued research and monitoring of climate change impacts. The second most frequently included principle is the fact base principle, where plans included a discussion of climate change projections, including impacts on the built environment. These discussions of projections varied widely on the methods, sources, and approaches used to generate these projections. Lowest scores were observed in uncertainty and implementation and monitoring, where there was acknowledgement of uncertainty (including using multiple IPCC concentration pathways) but a lack of discussion on how various scenarios were developed, and implementation and monitoring was most commonly associated with inclusion of mainstreaming actions.

The plan quality evaluation utilizes multivariate regression to describe if there is a correlation between community capacity, commitment, policy diffusion, and internal operations and plan quality scores. The regression indicated that plan quality is highly positively correlated with formal adoption of the adaptation plan, the community's planning department authoring the plan, and negatively correlated with the community being a recipient of state funding. The analysis indicated that the seven plan principles are not uniformly associated with community characteristics. Specific plan principles likely influence plan quality includes the presence of a state hazard mitigation planning mandate correlated with quality of plan goals (positive correlation), as is the publication of a climate mitigation plan and strategy scores (positive correlation). An interesting observation was that community median household income was negatively correlated with interorganizational coordination scores.

The article reflects on a number of considerations that may be underlying reasons for the plan quality and community characteristic correlations and variation observed. A major contributing factor to plan variability relates to the lack of established precedents, guidelines, or frameworks to inform the content of the plans reviewed. There remain gaps between theoretical approaches for planning under uncertainty and the approaches utilized in the plans reviewed, indicating that addressing uncertainty remains a significant weakness in the practice of adaptation planning. With regard to implementation, communities that involve elected officials and formally adopt a plan, these plans were consistently observed to have stronger goals and implementation and monitoring components, suggesting a positive role for elected official involvement. For extremely vulnerable communities, even with the presence of state funding, plans were consistently lower quality, suggesting a lack of planning capacity that would need to be remedied to increase plan quality. 
15. Woodruff, Sierra C., Sara Meerow, Missy Stults, and Chandler Wilkins. "Adaptation to Resilience Planning: Alternative Pathways to Prepare for Climate Change." Journal of Planning Education and Research, October 4, 2018, 0739456 X18801057. https://doi.org/10.1177/0739456X18801057.

Article Purpose: Present a plan evaluation of U.S. local resilience plan and U.S. local climate change adaptation plans to understand and describe similarities and differences between types of plans, their contents, and their characteristics. Present a critical analysis of how the various planning approaches address projected climate change impacts.

Methodology: The authors utilized plan assessment methodology from Stults and Woodruff (2017) to analyze 10 resilience plans developed from the100 Resilient Cities' program. These plans were then compared against the 44 climate adaptation plans that were previously examined in Woodruff and Stults 2016. Plans were qualitatively assessed using six plan quality principles (see typology below) and 124 plan criteria. A discrete binary score indicating the presence of a plan criteria was used to score each element. Semi-structured interviews with city staff key to resilience planning efforts, including Chief Resilience Officers, were conducted to understand city perspectives on resilience and approaches to climate change adaptation (7 interviews, $58 \%$ response rate).

\section{Typology of topics used in review of literature/plans/documents:}

Plan quality principles (Adapted from article Table 1. Plan Principles Used in Analysis)

1. Goals: A description of future desired conditions.

2. Fact base: Empirical data or other criteria that identify priority issues.

3. Strategies: Documents that guide decision making related to achieving community goals.

4. Public participation: Processes, techniques to engage community members and stakeholders.

5. Coordination: Processes, requirements for considering and engaging with other organizations that have an influence or the community is dependent upon.

6. Implementation and monitoring: Elements that indicate translation of plan strategies into actions or activities (e.g., timelines, budgetary guidance/funding, roles and responsibilities)

7. Uncertainty: Recognition and addressing uncertainty in future climate change through consideration of multiple scenarios, recognition of uncertainty.

Results and Conclusions: Resilience plans were observed to utilize a "systems" perspective when integrating approaches and information to manage risks. This includes utilizing a participatory process to collect information and seek input. Climate change adaptation plans, on the other hand, have a more robust analysis and discussion of local climate change impacts and uncertainties. These observations are reflected in the differences, such as resilience plans scoring higher on goals, public participation (nearly all plans reviewed included public engagement), while scoring lower on fact base criteria when compared to adaptation plans. 
Additionally, a brief discussion of interpretations of resilience is provided. It previously has been described as a measurable characteristic and also a normative way of thinking (Folke 2006). While in practice, some have observed that resilience is replacing sustainability in popular discourse (Davoudi et al. 2012) and also providing an organizing principle for creating more equitable cities, reducing vulnerability, and building on efforts in land use, comprehensive, and hazard mitigation planning (Berke 2008). Definitions of resilience vary across plans, such as some plans including social justice or equity. Others focus on shocks and some on stresses, and some consider resilience breaking down silos between administrative units and departments. Adaptation within adaptation plans always are defined in terms of, and in relation to, climate change. Both types of plans score relatively low on addressing uncertainty, however resilience plans score lower than adaptation plans. 


\subsection{Terminology Concept Examinations}

16. Davidson, J. L., C. Jacobson, A. Lyth, A. Dedekorkut-Howes, C. L. Baldwin, J. C. Ellison, N. J. Holbrook, et al. "Interrogating Resilience: Toward a Typology to Improve Its Operationalization." Ecology and Society 21, no. 2 (2016). https://doi.org/10.5751/es08450-210227.

Article Purpose: Resilience is an objective that has been cited alongside the need to address and prepare for global climate change. Because of the differences between its origin and current use, misunderstandings have emerged. The objective of this paper is to address misconceptions within the realm of resilience in order for the concept to be fully described. The authors approach this by analyzing resilience in conjunction with five chosen academic and practice domains.

Methodology: In order to evaluate resilience, five domains were chosen. These domains were chosen for being the most common schools of thought related to the concept. The authors then conducted literature reviews to analyze each domain and identify its characteristics such as definitions, and guidelines. A typology of ideal resilience types was then created, and the identified definitions were categorized based on the domains.

\section{Typology of topics used in review of literature/plans/documents:}

$\underline{\text { Resilience Domains }}$

1. Ecological Resilience (ER)

2. Socio-Ecological Resilience (SER)

3. Urban Resilience (UR)

4. Disaster Resilience (DR)

5. Community Resilience (CR) $\underline{\text { Resilience Conceptual Elements }}$

1. Persistence / Resistance

2. Absorption

3. Recovery

4. System identity retained

5. Renewal via self-reorganization

6. Adaptability

7. Transformability/transformation

8. Innovation

9. Capitalization

10. Preparedness

11. Vulnerability

12. Resilience building

13. Collective capacities

14. Collective processes

Results and Conclusions: The origins of resilience are particularly focused on an ecological system's ability to be subjected to change while maintaining its original state or function. Modern day resilience tends to focus on engineering resilience which encourages returning to an operational state (or bouncing back). Ecological resilience tends to refer to a stable equilibrium, while engineering resilience introduces multiple states of equilibrium because of multiple potential measures that can become solutions. Urban and disaster resilience are typically connected with mitigation and prevention. Transformative measures to help systems overcome hazards are considered alongside incremental mitigation and prevention. In this context, 
resilience should be viewed as a complex adaptive system (CAS) and has many influencing factors.

This article specifically prioritized cross scale interactions (CSI). Successful resilience planning includes collaboration from multiple fields. The results of the analysis indicate low levels of CSI between the resilience domains with the exception of socio-ecological resilience and ecological resilience as they place focus on CAS and have many influences. The authors argue that for resilience planning and implementation to become more effective, all types of resilience must be viewed as a CAS and its CSI studied.

\section{Folke, Carl, Stephen R. Carpenter, Brian Walker, Marten Scheffer, Terry Chapin, and Johan Rockstrom. "Resilience Thinking: Integrating Resilience, Adaptability and Transformability.” Ecology and Society 15, no. 4 (2010): 20. https://doi.org/10.5751/es- 03610-150420.}

Article Purpose: Present a conceptual framework of considering the role and definition of resilience within the context of complex socio-ecological systems (SES). The authors present three aspects that are important to the dynamics and development of complex systems: resilience, adaptability, and transformability.

Methodology: The authors present a conceptual framework based upon a literature review focused on prior discussions of SES and how resilience has been discussed in relation to the function or changes of a SES.

\section{Typology of topics used in review of literature/plans/documents:}

Key terms identified in the article:

1. Adaptability (adaptive capacity): The capacity of actions in a system to influence resilience.

2. General resilience: The resilience of any and all parts of a system to all kinds of shocks, including novel ones.

3. Resilience: The capacity of a system to absorb disturbance and reorganize while undergoing change as to retain function, structure and feedback, and identity.

4. Socio-ecological system: Integrate system of ecosystems and human society with reciprocal feedback and interdependence.

5. Specified resilience: The resilience "of what, to what". Related to a part of a system, a control variable, or to one or more types of shocks.

6. Transformability: Capacity to transform the stability landscape itself in order to become a different kind of system, create a fundamentally new system when ecological, economic, or social structures make the existing system untenable.

Results and Conclusions: Holling (1973) originally introduced resilience as a concept to describe and understand the capacity of ecosystems to remain in a state when subject to 
perturbations (also covered by Gunderson (2000), Folke (2006), and Scheffer (2009). Resilience has also been described as a return to equilibrium (Holling (1996) described this as "engineering resilience"). The authors describe the concepts of adaptability and transformability (see definitions in typology section) as related concepts to socio-ecological system resilience. Adaptability considers the "capacity of actors in a system to influence resilience (Walker et al. 2004), suggesting that adaptive capacity is the ability of a SES to maintain processes and functions while internal and external forces are imposed on the system. Transformability refers to the capacity of a SES to create a fundamentally new system or configuration when ecological, economic, or social structures/forces make the existing system not feasible (Walker et al. 2004).

The authors present the concepts of specified and general resilience that describe the practical implementation of the concept to describe and organize SES. Specified resilience refers to actions or efforts that relate to particular aspects of a system or related to a particular set of shocks. General resilience, on the other hand, is concerned with all types of shocks and what part of the system could be affected by the shock. The authors find these distinctions to be important because planning groups often use the specified resilience lens to focus on specific issues or problems, which may inadvertently limit options to address unexpected or novel issues. Moving from specified to general resilience is based upon cultural norms and beliefs and the shift may be hard to achieve outside of an acute shock or crisis (real or perceived).

\section{Lei, Yongdeng, Jing'ai Wang, Yaojie Yue, Hongjian Zhou, and Weixia Yin. "Rethinking the Relationships of Vulnerability, Resilience, and Adaptation from a Disaster Risk Perspective." Natural Hazards 70, no. 1 (January 1, 2014): 609-27. https://doi.org/10.1007/s11069-013-0831-7.}

Article Purpose: A theoretical framework is presented for describing the relationships between vulnerability, resilience, and adaptation in the context of social-ecological systems (SES), disaster risk management, and sustainability of SES. The article provides basic definitions of the three concepts and their relationships under various interpretations (vulnerability perspectives, disaster risk reduction perspective) and an empirical case study of these concepts through the lens of agricultural drought hazards, and land use and crop rotation management approaches.

Methodology: A literature review of prior SES scholarly literature is presented alongside an empirical case study of agricultural drought in the village of Beidian, China in June to July 2012. The case study methodology is based on unstructured interviews with local village managers along with baseline hydrologic data from the Chinese National Agricultural Scientific Data Sharing Center. 


\section{Typology of topics used in review of literature/plans/documents:}

Relevant definitions (Multiple presented in the article, summary definitions provided below): 1. Vulnerability: From a natural hazards perspective, exposure conditions that make people and places vulnerable to extreme natural events, societal resistance of resilience to hazards, and integration of exposures and societal resilience with a specific on particular regions (Cutter and Finch 2008, Kasperson and Kasperson 2005, Cutter, Boruff, and Shirley 2003).

2. Resilience: From a natural hazards perspective, broadly defined as the capacity to resist and recovery from disaster losses (Zhou et al. 2010).

3. Adaptation: The process, action, or ability of an individual or system to improve inherent characteristics to accommodate change, such as through social learning. This includes moderating harm and exploiting beneficial opportunities.

Results and Conclusions: The authors present conceptual framing for the relationships between vulnerability (V), resilience (Re), and adaptation (A). The first context in which the relationship is discussed is the "vulnerability preference", a relationship primarily used by climate change researchers and disaster risk researchers. In the vulnerability preference, exposure, sensitivity, and adaptive capacity, along with resilience, should be included in the analytical framework of vulnerability (IPCC 2001, Marshall et al. 2010). In the second context, the "resilience preference", resilience is defined as the response capacity to interferences or changes, including short term coping capacity and long-term adaptive capacity. Resilience considers the ability of a system to self-organize and can build capacity for learning and adaptation (Adger et al. 2005). Vulnerability, within the resilience preference context, is the opposite of resilience, describing when a system loses resilience it is susceptible to changes that previously could be absorbed by the system. The article also presents overlapping interpretations of these elements rather than existing in a mutually exclusive relationship.

The authors present a conceptual framework for interpreting these resilience, vulnerability, and adaptation concepts within the context of a "hit-damage-recovery-learning" cycle, which is prominent in disaster risk management. In this cycle, resilience is the ability of a system to resist and recover from loss in the shortest possible amount of time with minimal or no outside assistance. Following this shock to the system, there are periods for improvement or periods where reduction in vulnerability is possible through SES changes. These periods can be broken up into "short-term adjustments"(STA) and "long-term adaptation" (LTA). STA reflects activities that reduce vulnerability for a current system state and bounce back to function. STA activities are often temporary and there may be many over time. LTA reflects significant changes in system states that increase the ability to manage risk and impacts, are characterized by increasing flexibility for problem solving, and are often addressed through social learning and innovation from prior shocks. 
19. Meerow, S., and J. P. Newell. "Resilience and Complexity A Bibliometric Review and Prospects for Industrial Ecology." Journal of Industrial Ecology 19, no. 2 (April 2015): 236-51. https://doi.org/10.1111/jiec.12252.

Article Purpose: Resilience involves many internal and external factors of a system in question. Thus, resilient systems can be synonymously called complex systems. This article conducts a review of resilience literature in order to highlight the different schools of thoughts in definitions and the different characteristics seen within each respective group. Given the rise of resilience as a concept, it must be studied and understood more. This paper provides potential beneficial suggestions for those in the field to implement, in order to advance the concept.

Methodology: This study utilizes the techniques of direct citations, co-citations, and weighted direct citations. These techniques were collectively used to create a co-citation network. The network showed how often citations were seen together and how similar their references were. The studied documents were found using Web of Science. They were further classified into two datasets. To identify emerging research communities and authors within the datasets, the program Gephi, an open source visualization software was used to analyze the data. This program allowed the authors to sort and visualize the data in terms of networks and linkages/patterns. The resultant visualization displayed bubbles for each author, where its size was proportional to the number of citations, and it was divided based on the driving characteristic of each community. Each community, therefore, had respective overlying definitions and conceptualizations of resilience.

\section{Typology of topics used in review of literature/plans/documents:}

Datasets and communities seen in literature

Resilience complexity dataset:

1. Ecological resilience

2. Socio-ecological resilience

3. Marine ecosystems

4. Complexity and networks

5. Organizational risk and resilience

Industrial ecology (IE) resilience dataset:

1. Topically diverse

2. Risk and resilience in technical systems

3. IE and resilience

4. Urban systems

5. Agricultural systems

Results and Conclusions: The research communities were inherently divided. Ecological resilience (community 1 ) was seen the most frequently within the resilience-complexity dataset. This was followed by socio-ecological systems (community 2). These two communities had 
linked and even had many of the same authors lead their studies. The remaining three communities were more isolated and had a very small group of authors. This resulted in similar schools of thought being promoted.

The results of the IE-resilience dataset showed that resilience is not being used in practice very often. In addition to this, resilience is also viewed with great discrepancies to how their characteristics are dealt with. The publications varied and gave no clear trend on their view of resilience's complexity and whether it was static or dynamic. However, when analyzed using the co-citation network, the most emergent and contributing authors, Hollings and Carpenter et al. promoted dynamic systems of equilibriums. This wide range of results show that resilience has not fully been studied in order to operationalize it. More collaboration is needed between the IE and resilience scholars communities to foster advancement.

This study suggests that to plan for resilience in our modern day, it must be adaptive and thus dynamic, and even transformative systems of resilience may be more beneficial. Modern day urban resilience is considered to be the answer. Studying it revealed three types of groupings: industrial, political, and urban ecology. If these three ecologies collaborated, the authors believe that resilience as a concept would be much more understood.

\section{Meerow, S., J. P. Newell, and M. Stults. "Defining Urban Resilience: A Review." Landscape and Urban Planning 147 (March 2016): 38-49. https://doi.org/10.1016/j.landurbplan.2015.11.011.}

Article Purpose: Resilience planning has seen a rise coinciding with the increasing importance of addressing climate change. This paper seeks to clarify the existing definitions of resilience, with the hopes of increasing its operationality. Based on the literature review, conceptual 'tensions' or areas of disparity, are identified and ultimately, a definition of resilience is proposed that is inclusive and flexible enough to enable collaboration among, and use by, diverse disciplines.

Methodology: Scopus and Web of Science were used to identify literature on urban resilience between 1973 and 2013. The final urban resilience dataset included 172 individual publications from varying fields. Co-citation analysis was then conducted to quantitatively evaluate the chosen literature based on the frequency of two or more studies being cited together within a document. Based on citation frequency, unique definitions were taken from the studies, resulting in 25 distinct definitions, which were then compared to the six conceptual tensions. A new definition is then presented.

\section{Typology of topics used in review of literature/plans/documents:}

Conceptual tensions in definitions of urban resilience

1. Characterization of 'urban' 
2. Notion of equilibrium

3. Resilience as a positive concept

4. Pathway to resilience

5. Understanding of adaptation

6. Timescale of action

Fundamental questions related to urban resilience

1. Who?

a. Who determines what is desirable for an urban system?

b. Whose resilience is prioritized?

c. Who is included (and excluded) from the urban system?

2. What?

a. What perturbations should the urban system be resilient to?

b. What networks and sectors are included in the urban system?

c. Is the focus on generic or specific resilience?

3. When?

a. Is the focus on rapid onset disturbances or slow onset changes?

b. Is the focus on short term resilience or long-term resilience?

c. Is the focus on the resilience of present or future generations? 4.Where?

a. Where are the spatial boundaries of the urban system?

b. Is the resilience of some areas prioritized over others?

c. Does building resilience in some areas affect resilience elsewhere?

5. Why?

a. What is the goal of building urban resilience?

b. What are the underlying motivations for building urban resilience?

c. Is the focus on process or outcome?

Results and Conclusions: Twenty five definitions of resilience were identified from the studied literature. These definitions indicate that resilience is not consistently described and variability exists. The inconsistencies seen in existing literature cause discrepancies in urban resilience planning, ultimately negatively affecting all respective groups from planners to stakeholders.

To address observed inconsistencies of existing literature, the authors propose the following definition of urban resilience:

Urban resilience refers to the ability of an urban system and all its constituent socio-ecological and socio-technical networks across temporal and spatial scales to maintain or rapidly return to desired 
functions in the face of a disturbance, to adapt to change, and to quickly transform systems that limit current or future adaptive capacity.

The authors propose this structured, but flexible definition of urban resilience that clarifies inconsistencies while retaining inclusivity. This unified definition is useful for supporting a process in which multiple groups who are affected and involved can be recognized. Therefore, the definition considers for whom, what, when, where, and why (five W's of urban resilience) must be considered in the planning process to best meet the fundamental needs of those involved.

\author{
21. Meerow, S., and M. Stults. "Comparing Conceptualizations of Urban Climate Resilience \\ in Theory and Practice." Sustainability 8, no. 7 (July 2016). \\ https://doi.org/10.3390/su8070701.
}

Article Purpose: Resilience has seen a large increase in the context of addressing the impacts of climate change. This paper provides insight into how both academic researchers and practitioners define and operationalize the concept of resilience. Ultimately, by addressing these potential differences, the purpose of this article is to foster better understanding of the similarities as well and promote unification.

Methodology: An extensive literature review, comprising 172 articles, spanning from 1973 to 2013 was completed. Articles with the terms "urban resilience" and "resilient cities" in their title, abstract, or keywords were selected. The emerging characteristics of resilient urban systems were extracted from these articles and analyzed. A survey instrument was then developed to evaluate how urban climate change resilience is defined and characterized by practitioners and how it compared to the existing literature.

\title{
Typology of topics used in review of literature/plans/documents:
}

Resilience Characteristics identified from literature:

1. Robustness: Ensuring municipal wide infrastructure and organizations can withstand external shocks and quickly return to the previous operational state

2. Redundancy: Having backup systems, infrastructure, institutions, and agents

3. Diversity: Ensuring a diverse economy, infrastructure, and resource base (e.g., not relying on single mode of operation, solution, or agent/institution)

4. Integration: Making sure that plans and actions are integrated across multiple departments and external organizations

5. Inclusivity: Ensuring that all residents have access to municipal infrastructure and services, including providing an opportunity for all people to participate in decision making processes 6. Equity: Ensuring that the benefits and impacts associated with actions are felt equitably throughout the municipality

7. Iterative Process: Creating a process whereby feedback and lessons learned are continually used to inform future actions 
8. Decentralization: Decentralizing services, resources, and governance

9. Feedback: Building mechanisms so that information is rapidly fed back to decision makers or system operators

10. Environmental: Protecting natural systems and assets

11. Transparency: Ensuring that all municipal processes and operations are open and transparent

12. Flexibility: Making municipal processes and operations are open and transparent

13. Forward Thinking: Integrating information about future conditions

14. Adaptive Capacity: Ensuring that all residents have the capacity to adapt to climate change

15. Predictable: Ensuring that systems are designed to fail in predictable, safe ways

16. Efficiency: Enhancing the efficiency of government and external operations

Results and Conclusions: Resilience definitions from practitioners tended to provide much more variation than from academia. From the literature review, 16 relevant characteristics to resilience were identified.

In academic literature on resilience, the trend seems to be moving away from static, engineering resilience defined by "bouncing back," to more of the traits of ecological resilience which is focused more on "bouncing forward." Practitioners from the survey however, placed importance on robustness or "withstanding external shocks and quickly returning to the previous operational state," thus being more in alignment with the "bouncing back" approach to resilience. Both academics and practitioners included the importance of forward thinking into their definitions. However, this must be done in moderation as practitioners provide warnings against placing too much emphasis on one type of threat instead of thorough planning measures. When asked about the importance of adaptive capacity and flexibility, practitioners did not view it as important. Diversity, flexibility, and redundancy were remaining characteristics that were considered fundamental in literature but were rarely mentioned by practitioners.

Although there are inconsistencies, there are some areas of similarities that are promising. Practitioners agree with the environment being important for resilience. This was also seen in academic literature relating back to the origins of ecological resilience. These similarities and differences pose new avenues for future research.

22. Moser, S., S. Meerow, J. Arnott, and E. Jack-Scott. "The Turbulent World of Resilience: Interpretations and Themes for Transdisciplinary Dialogue." Climatic Change 153, no. 1-2 (March 2019): 21-40. https://doi.org/10.1007/s10584-018-2358-0.

Article Purpose: Present a thematic review of literature on different disciplinary interpretations of resilience. Distill the results of the review to identify seven themes of resilience discourse and identify implications for increased disciplinary discourse (transdisciplinary) across the identified interpretations of resilience. 
Methodology: The challenge of transdisciplinary research and dialogue around the concept of resilience was identified through an Aspen Global Change Institute workshop in December 2015. The ideas and challenges identified in this workshop were investigated further through a metaanalysis literature review of resilience review papers. Resilience review papers were identified through a Scopus database search on the terms "resilience AND urban OR risk OR ecological OR community OR hazards OR disasters OR infrastructure OR climate OR 42sychology*, which yielded 155 results, reduced to 52 review papers in the domains of urban studies, hazard/disaster reduction, ecology, psychology, child/human development, international development, climate change adaptation, engineering, geography, archeology, energy, epidemiology, public administration/policy, food systems, along with other fields and perspectives.

Results and Conclusions: Through the systematic meta-analysis of resilience review papers, the authors present seven thematic results with implications for transdisciplinary resilience research and practice:

1. The distinction between resilience as a system trait, process, or outcome: Researchers in fields of ecology and engineering often focus on resilience as a system property, while social science fields focus on resilience as a process or outcome. A number of traits commonly associated with each interpretation are identified, such as redundancy, connectivity, modularity for resilience as a system trait; embracing change and uncertainty, embracing equity/inclusivity/participatory decision processes for resilience as a process; and safety after failure, reliability, robustness for resilience as an outcome.

2. The importance of resilience as a strategy for dealing with uncertainty: Resilience is an organizing concept and approach for dealing with complexity and uncertainty within systems, as systems change, and between systems.

3. A shift from understanding resilience to active resilience building: This interpretation considers that resilience is not an underlying system property, but can be developed or results from system interactions or interventions. Resilience is a trait that is developed or built over time, represents the evolution of a system, or built through adversity (health and psychology literature).

4. The incorporation of the concept of transformation into resilience: The concept of bouncing back after a disaster or shock is central to this interpretation (common in ecological and engineering interpretations). Incorporation of the idea that a transformation or system change is an important element.

5. The normative interpretation of resilience: This interpretation considers that resilience has shifted from a purely analytical and descriptive concept to a set of norms, such as a goal, management approach, or philosophy or way of thinking. This interpretation includes statements or goals that indicate an actor or organization wishes to be resilient, as opposed to using it as a descriptor of the underlying processes or systems of that actor.

6. A growing emphasis on measuring and evaluating resilience: Measurement, monitoring, and evaluation of resilience as a concept has broadly been discussed as an area of interest in the fields of engineering, agriculture, health sciences, and the electricity sector. There is variation 
across sectors on approaches to measure and discussions about whether it is worthwhile to measure resilience as a concept or the measurement of outcomes.

7. Common critiques of resilience across disciplines and fields: There are common critiques of the use of resilience as a concept that are observed across disciplines and fields. Some of these include confusion around multiple meanings of resilience, concern over lack of critical assessment of translating the concept from natural to social systems, implications of returning to a prior state, and the use of the term related to normative questions.

\title{
23. Romero-Lankao, P., D. M. Gnatz, O. Wilhelmi, and M. Hayden. "Urban Sustainability and Resilience: From Theory to Practice.” Sustainability 8, no. 12 (December 2016). https://doi.org/10.3390/su8121224.
}

\begin{abstract}
Article Purpose:
This article provides a synthesis of theories of urban resilience and sustainability that serve as analytical or conceptual frameworks for practice. This conceptual review is the review article of a compilation of articles published in Sustainability that describe various theories and the practice of urban sustainability and resilience, with a focus on how different definitions complement or contradict one another.
\end{abstract}

Methodology: The article relies on a literature review of other scholarly work submitted to a special publication of the Sustainability journal titled "Urban Resilience and Urban Sustainability: From Research to Practice" (2016).

\section{Typology of topics used in review of literature/plans/documents:}

The authors suggest a definition of urban areas as social-ecological systems which represent 5 domains that can used to describe various development patterns, approaches to sustainability and resilience:

4. Socio-demographics

a. Sustainability approach: Emphasis on limiting population growth and addressing inequality

b. Resilience approach: Equity in distribution of benefits and risks

5. Economy

a. Sustainability approach: Reductions in resource use and pollution

b. Resilience approach: Flexibility and redundancy

6. Technology

a. Sustainability approach: From higher to lower emphasis on the intrinsic value of nature

b. Resilience approach: Soft, flexible systems

7. Environment

a. Sustainability approach: Many intrinsic values in nature

b. Resilience approach: Bounce forward (not bounce back) 


\section{Governance}

a. Sustainability approach: Emphasis on collaborative and inclusive decision making

b. Resilience approach: Emphasis on consideration of and collaboration across scale; adaptive approaches

Results and Conclusions: Based on a review of the articles submitted to the special issue, the authors find that challenges remain to identify consistent definitions of resilience and sustainability. Of the definitions that have been observed, they are subject to various approaches, interpretations, and subject specific framing. They differ in terms of how they are used in a theoretical context and differ in their operational implementation.

Discussions on the use and interpretation of sustainability have their origins in the fields of biology and ecology. In these contexts, sustainability refers to the rate of consumption of a resource before ecological effects are observed (e.g., changes in function and structure). From a current development perspective, sustainability has been discussed in reference to the environment and economy (e.g., "triple bottom line"; environment, economy, equity), which address issues related to temporal differences between when impacts and consequences take place and are observed. Various interpretations of sustainability consider socio-demographic considerations, but vary in the level of significance of how they are considered. Some interpretations focus on reducing the intensity of emissions per unit of consumption, while others focus on the reduction of units of consumption (e.g., population reduction), and others focus on issues related to environmental justice and social equity. The authors suggest that in a current environmental and economic focus on sustainability, issues related to social equity are reduced to minor consideration or not considered at all.

Discussions on the use and interpretation of resilience are cited as having their roots in the fields of ecology, engineering, and psychology. Hazards, stressors, or political turmoil based interpretations of resilience generally adopt an interpretation of "fail-safe" engineering, indicating that a system will return back to steady state over time and can absorb shocks or stressors. This "bounce-back" interpretation infers the ability to predictably estimate the use of resources and ecosystem services. Within ecological perspectives, a "safe-to-fail" perspective is adopted indicating that a system (generally an ecological system) can absorb or adapt to new conditions and remain within a critical threshold before changing to a new system state. Within this interpretation, resilience is not returning back to steady state, but rather the ability of a complex system to change and transform in response to internal and external factors.

24. Wied, M., J. Oehmen, and T. Welo. "Conceptualizing Resilience in Engineering Systems: An Analysis of the Literature." Systems Engineering 23, no. 1 (January 2020): 3-13. https://doi.org/10.1002/sys.21491.

Article Purpose: The concept of resilience is one that is widely contested and as a result, the characteristics of a resilient system are not yet definitive. This paper analyses emergent 
definitions in current literature in order to clarify misconceptions. Systems are categorized based on the type of impacts they face, and if they allow for advancement. The study provides a typology of resilient systems and gives decision makers potential solutions to questions that may be asked in the design process.

Methodology: A resilient system depends on three variables, uncertain conditions, resilient properties, and system performance. It is also capable of bouncing forward or back given the system's properties. Employing this approach, existing literature was reviewed and the scope was narrowed to include only documents of direct relevance to engineering systems. Scopus was used and all literature reviews that contained the words "resilience" and "review" with connections to each other were included. This search identified 111 articles. Only the articles that specifically defined resilience were further chosen, narrowing the sample to 21 articles. The review identified 251 unique definitions of resilience based on varying system types. The definitions were categorized into system types that the authors introduced. The results were

\section{Typology of topics used in review of literature/plans/documents:}

$\underline{\text { Resilience variables taken from literature }}$

$\begin{array}{lll}\text { Resilience "of what" } & \text { Resilience "to what" } & \text { Resilience "how" } \\ \text { 1. Function } & \text { 1. Disruption } & \text { 1. Recovery } \\ \text { 2. State } & \text { 2. Change } & \text { 2. Absorption } \\ \text { 3. Structure } & \text { 3. Event } & \text { 3. Adaptation } \\ \text { 4. Degradation } & \text { 4. Damage } & \text { 4. Reaction } \\ \text { 5. Loss } & \text { 5. Adversity } & \text { 5. Improvement } \\ \text { 6. Identity } & \text { 6. Risk } & \text { 6. Prevention } \\ \text { 7. Growth } & \text { 7. Uncertainty } & \text { 7. Minimal/graceful } \\ \text { 8. Behavior } & \text { 8. Turbulence/variation } & \text { deterioration } \\ \text { 9. Control } & \text { 9. Failure } & \text { 8. Anticipation } \\ & & \text { 9. Coping } \\ & & \text { 10. Survival }\end{array}$

Results and Conclusions: When planning for resilience, three conceptual questions must be answered: resilience "of what," "to what," and "how." When asked resilience "of what" most literature mentioned restoration of system functions, followed by returning to its original state, as is consistent with classic engineering resilience. Less mentioned were categories related to the actual state of the system, such as system identity. These results suggest that factors affecting the system can be contributors to the resilience process or are outcomes themselves. 
Analyzing resilience "to what" showed many stresses to systems. Stresses were both short term and long term and also internal and external of the system. Many articles simply made mention of change of the system taking place without any notable effect/impact being seen.

Resilience "how" showed that academic literature proposed large variation of qualities deemed important. Resilience should be able to bounce back as well as offer means to bounce forward from impacts. Academic literature argues over this distinction, as well the fact that resilience can either be reactive to the situation, or proactive in advance of the situation.

The key distinctions seen when studying resilience literature provided a typology of resilient systems characteristics, as well as three ways to define and judge the performance of resilient system characteristics. This study suggests that characteristics of resilient systems must be judged on if contributes to or defines the resilience process; if it has positive, negative, or both impacts and if its existing state of affairs is an ideal outcome or must be improved upon. Finally, resilience must also be judged on the type of measures that are implemented. All three conceptual resilience questions must be addressed, and the best measures must be implemented to advance resilient systems. 


\subsection{State of Practice, Implementation, or Research Examinations}

25. Bierbaum, R., J. B. Smith, A. Lee, M. Blair, L. Carter, F. S. Chapin, P. Fleming, et al. "A Comprehensive Review of Climate Adaptation in the United States: More than before, but Less than Needed." Mitigation and Adaptation Strategies for Global Change 18, no. 3 (March 2013): 361-406. https://doi.org/10.1007/s11027-012-9423-1.

Article Purpose: A review of existing and planned adaptation activities of federal, state, tribal, and local government climate change adaptation actions were reviewed and analyzed with the objective of characterizing that state of adaptation planning and action in the United States. In addition to characterize the state of planning and action, the article highlights barriers to implementing adaptation actions and describes scientific and policy advances necessary to increase the use of adaptation planning and action implementation.

Methodology: A literature review of documents collected from those submitted in preparation for the 2013 National Climate Assessment and 30 external documents from peer reviewed and gray literature. A majority of the articles reviewed were published after 2007. A semi-structured content analysis was conducted to tag relevant content with adaptation related categories (e.g., planning, implementation, natural systems, urban, federal, tribal, local, barriers).

\section{Typology of topics used in review of literature/plans/documents:}

Climate change adaptation action keywords

1. Planning

2. Implementation

3. Natural systems

4. Urban

5. Federal

6. Tribal

7. Local

8. Barriers

Classification of adaptation related content into areas where action takes place

1. Scale

2. Sector

3. Geographic location

4. Type of adaptation activity
a. Planning
b. Infrastructure
c. Policy

Results and Conclusions: Overall, the literature review found that incremental changes are the primary actions being described in climate change adaptation planning and implementation documents, which the authors contend are insufficient to address the projected changes in 
climate and associated impacts. Similarities in actions across sectors involved mainstreaming climate change considerations into existing processes, plans, and policies, along with proposing no regret and low regret strategies or actions. Common barriers relate to lack of funding for planning and implementation, policy, institutional barriers, and difficulty anticipating climate change impacts based on current information on projected impacts.

Current adaptation processes observed in the literature review focus on a series of discrete steps. In the first step, governments and organizations identify and understand risk, vulnerabilities, and opportunities associated with various case studies of climate change impacts, using scenario analysis, sensitivity analysis, and peer sharing of information. The next step of planning, assessing, and selecting options comprises a participatory process that incorporates local context specific information where stakeholders and governing bodies work collaboratively to identify and articulate problems and identify solutions that represent stakeholder values. The implementation step primarily focuses on the evaluation and selection of adaptation actions. After implementation, monitoring and evaluation utilizing recognized and scientifically valid process and outcome based indicators is necessary. The last step represents these steps as an iterative and recursive process where these strategies are periodically updated and revised to incorporate new information about future conditions, including non-climate information (e.g., population growth, development patterns, economic conditions, changes in uncertainty in any of these factors).

Across sectors and scales, there were a number of common research and development needs that would address the barriers observed:

1. Research on effective policy making processes: Due to fragmentation at different levels of government, differences in impacts and policies across geographic scales, and sharing of knowledge, policy research is needed that provides options to describe effective governance structures, stakeholder communication approaches, and knowledge sharing.

2. Developing capacity to organize and deliver usable climate change information: There is a translational research need to enable users of climate change data and information the ability to integrate their own information to evaluate how climate change and other stressors may affect their unique conditions.

3. Research into decision making in light of uncertainty: The presence of uncertainty in future climate impacts, processes to plan for these impacts, and the effectiveness and cost of solutions hinders actions. 
26. Koliou, Maria, John W. van de Lindt, Therese P. McAllister, Bruce R. Ellingwood, Maria Dillard, and Harvey Cutler. "State of the Research in Community Resilience: Progress and Challenges." Sustainable and Resilient Infrastructure 5, no. 3 (May 3, 2020): 13151. https://doi.org/10.1080/23789689.2017.1418547.

Article Purpose: The results of a literature review are presented that examine how various research approaches have considered definitions and approaches to characterize and model natural hazards focused community resilience. The article provides results and recommendations for future research into sections related to physical infrastructure systems, social systems, and economic systems.

Methodology: A descriptive literature review of peer reviewed articles and government reports is conducted on natural hazards focused community resilience from the fields of engineering, environmental science, sociology, psychology and economics was performed. The review of articles focuses on identifying definitions of resilience, initiatives supporting the development or practice of community scale resilience, and a series of system specific reviews of the state of research and future needs.

\section{Typology of topics used in review of literature/plans/documents:}

Community resilience research by discipline:

1. Facility and system resilience

a. Physical infrastructure systems

i. System interdependencies

ii. Buildings and critical infrastructure

b. Lifeline systems

i. Power systems

ii. Water and wastewater systems

iii. Natural gas systems

iv. Transportation systems

2. Social systems (which includes conceptual studies informing definitions, theoretical studies improving understanding of resilience, methodological studies improving the measurement of resilience, and empirical studies identifying factors associated with social system response and recovery)

3. Economic systems (which include modeling approaches, such as input-output modeling, computable general equilibrium (CGE) modeling and modifications such as a spatial CGE model and a social accounting matrix, and econometric models)

Results and Conclusions: Definitions of resilience span the various fields of research. Notable conceptual frameworks to define resilience include Holling (1973) which defines resilience as the ability of ecological systems to absorb and bounce back and Gordon (1978) for resilience of physical structures. Mileti (1999) and Paton and Johnston (2001) both adopt these concepts for 
social systems to use resources to promote recovery. Folke et al. (2002) includes human and social factors as part of SES and includes learning and adaptation as parts of resilience. Rose and Liao (2005) builds upon Folke et al. (2002) and suggests 2 components to resilience: inherent resilience (economic substitution for damaged elements of infrastructure) and adaptive resilience (economic policies implemented ex post to address shortcomings in delivery of goods and services). The review suggests that a three part view of resilience has been prevalent in the period of 2008 to 2018 and has focused on the activities of reducing impacts or consequences, reducing recovery time, reducing future vulnerabilities. International or national scale efforts often adopt various scales of these three concepts (e.g., IPCC Assessment Report 4 and IPCC AR5).

Each of the categories of fields or systems represent distinct approaches to community resilience. The article describes the following distinguishing characteristics and areas of future work. For facilities and system resilience, efforts to develop resilience frameworks need to be expanded or generalized to address climate related hazards, correlate social and economic attributes, and include the development of risk informed decision making tools. For physical infrastructure systems, subsequent research should expand methods and case studies that include assessment of non-hospital buildings, methods to correlate infrastructure damage with social and economic functions, non-earthquake natural hazards, and efforts to include the concepts of adaptation and learning. For lifeline systems, future studies are needed to address the interdependencies between systems, their degradation and subsequent restoration, and how these interdependencies affect social functions. This also includes evaluating social expectation for performance of these systems and how individuals or groups may substitute elements of a system to maintain function (e.g., transportation mode switching). For social systems, prior research has focused on describing community resilience in several ways. For example, presenting conceptual studies that inform definitions of resilience, methodological studies to advance the capability to measure resilience, and empirical studies that identify factors related to social system response and recovery at community scales. For economic systems, future work should consider various economic modeling approach (e.g., input-output, computable general equilibrium) and integrating these with other modeling approaches, notably social and engineering models in a manner that allows for describing the temporal aspects of resilience (e.g., pre-event, post-event, through recovery).

\section{B Perkins, D Ojima, R Corell. "A Survey of Climate Change Adaptation Planning." Heinz Center, 2007.}

Article Purpose: The report provides the results of a review of gray literature focused on climate change adaptation planning guidebooks and frameworks, and a review of international adaptation planning efforts case examples taking place as of the report's 2007 publication. The review of adaptation planning guidebooks and frameworks qualitatively describes eight guidebooks/frameworks reviewed and presents comparison criteria that represent the content, policy applications, and participatory elements of the guidance. (Note that this annotated 
bibliography entry only covers the findings and examination of the adaptation planning guidance and frameworks. It does not review the case studies of adaptation planning presented in the publication.)

Methodology: The report presents eight qualitative criteria to evaluate the adaptation planning guides and frameworks, and utilizes a three point discrete ordinal scale to represent the level of discussion presented in each document reviewed (e.g., discussed in depth, in some detail, very little detail or not discussed). The report indicates that the comparison is intended to provide indication of available information on adaptation planning, but does not represent best practices or trends in the field or practice of adaptation planning.

\section{Typology of topics used in review of literature/plans/documents:}

The eight criteria for examining the guides and frameworks are:

1. Applicability to different levels of government and types of environmental challenges: The document describes details that have broad applicability to various governance systems, environmental conditions, and community structures/values.

2. Sufficient detail for policy construction: The document provides details on processes or steps to successfully conceive a policy to its implementation.

3. Provides a decision making framework: The document provides aids to evaluate opinions, timing of action/implementation, and assess costs and benefits or other methods to describe the efficacy of proposed actions.

4. Includes means to assess such factors as sensitivity, adaptive capacity, and vulnerability: The document provides details, steps, or methodology to assess factors commonly associated with adaptation planning.

5. Suggests steps for adaptive actions: The document includes information on case studies, examples of prior implementation, or best practices.

6. Covers implementation: The document discusses policy implementation and enforcement. 7. Links to additional resources provided: The document provides resources for learning more about climate science, policy solutions, and presents this information in an easy to understand format.

8. Includes stakeholder: The document provides information on how to structure a participatory process, identify representative and diverse stakeholders, and include their input and involvement in a planning process.

Results and Conclusions: The report describes a qualitative assessment of eight international adaptation guidance documents. There was observed variability in the criteria covered, suggesting various planning approaches, but all documents provided some level of recommended actions, policies, or mitigation action. Of the guides and frameworks reviewed, documents published by King County, Washington USA and ICLEI, and New Zealand's Climate Change Office were rated the most highly. The King County and ICLEI document, "Preparing for Climate Change: A Guidebook for Local, Regional and State Governments" (2007), is a guidance document focused on aiding local and regional governments and provide step by step guidance on assembling a planning team and its leadership, assessing and selecting sectors for 
action, a qualitative process for assessing vulnerability, and options for potential actions. The New Zealand Climate Change Office's "Coastal Hazards and Climate Change: A Guidance Manual for Local Government in New Zealand" (2004) is a document that is tailored for coastal communities and their local governments. However, the structure presented in the document, risk assessment methods, and principles for selecting and managing actions are applicable more broadly than only coastal locations. The document provides a well-structured decision making framework and risk assessment methodology, establishes seven principles for management options (e.g., land use planning, avoided development, property acquisitions, building codes).

28. Sellberg, My M., Cathy Wilkinson, and Garry D. Peterson. "Resilience Assessment: A Useful Approach to Navigate Urban Sustainability Challenges. ” Ecology and Society 20, no. 1 (2015): 43. https://doi.org/10.5751/ES-07258-200143.

Article Purpose: Communities are becoming more involved with integrating resilience into their planning. However, it is not always known what being resilient is composed of. This article holistically measured the resilience assessment process of a local government in Sweden. The Resilience Assessment Workbook (RAW) was also assessed to see how it aided this process.

Methodology: The authors use multiple measures to evaluate the process. Participant observations, multiple types of interviews, and conducting planning meetings were used to thoroughly gain insight on how involved persons view the entire planning process. Surveys, and review of current official documents were also conducted to provide more data. All data was analyzed, mostly qualitatively and emergent themes were documented and categorized.

\section{Typology of topics used in review of literature/plans/documents:}

$\underline{\text { Structure and scope of resilience assessment }}$

1. Of what (focal systems)
a. food supply
b. water supply
c. transportation
d. employment

2. To what (specific threats)
a. energy crisis
b. financial crisis
c. climate crisis
d. planetary boundaries

3. So what? (impacts)
a. society
b. economy
c. environment 
4. Now what? (strategies for resilience)

a. identify existing and new strategies to strengthen resilience in the face of these crises

Results and Conclusions: Most participants agreed on the fact that their community's resilience assessment enabled them to view resilience as a dynamic system. Participants never placed focus on seeing the community as a nexus, with everything being connected. Resilience must view systems as complex and integrated.

According to current planners, the community lacked guidance on how to deal with potential future threats. This workshop allowed these discussions to begin. The planning process must incorporate a longer period of considering potential threats and consider these uncertainties as an actual possibility. Many planners noted that specific areas like food and shelter were not included at all in the process. Resilience can also help plan for longer term issues whereas current measures being implemented only focus on a hazard's short term effects.

The planners were also allowed to think about sustainable work in their own planning process. Although many plans indicate that work must be done in order to achieve sustainability, the concept is still very vague to many practitioners. The authors believe that a community's resilience assessment plan must have the potential to allow for sustainable development to take place. Entire life cycle assessments of a process must take place and its impacts and the consequences must also be fully considered, and sustainability must not be sectorized from the department itself.

Resilience issues are complex in nature and should be treated as such. Current resilience assessments have weaknesses. Collaboration between different scales were not present in the community's resilience plan. In addition to this, the discussions allowed planners to identify measures that have not been effective within their respective resilience assessment plans. 


\section{Discussion}

This annotated bibliography reviewed 28 articles related to resilience, adaptation, and sustainability ("RAS") planning, specifically presenting methodologies to assess or evaluate elements of these types of plans or theoretical frameworks for how these concepts are related. The review informs the development of a methodology that can be used to subsequently assess the content of resilience, adaptation, and sustainability planning guidance, instructions, and requirements for practice. This section provides a discussion of observations on common criteria, themes, or findings presented in the annotations, organized into the three thematic topics (as described in chapter 2).

\subsection{Overview of Results and Themes Observed}

\subsubsection{Plan Evaluation Studies and Methodology Examination}

A field of planning research that has evolved over the past 10 years to 15 years has increasingly focused its attention on examining planning documents published by local governments to understand and attribute plan elements and qualities to community specific contextual factors or observed interventions. These examinations derive from the field of urban planning, but have been increasingly applied to a broad array of planning objectives that span multiple fields (e.g., engineering, disaster science, environmental science, climate science, and public administration). In the articles reviewed in Section 3.1, plan assessment focused on the evaluation of comprehensive planning documents, reviews of local hazard mitigation plans developed in response to the Disaster Mitigation Act of 2000, and sustainable development as an objective of planning. In more recent years, this focus has expanded into an increasingly broad set of planning objectives including resilience and climate change adaptation planning.

\section{Plan Evaluation Methodology}

While the topical focus of plan quality evaluation studies has shifted over the years, the general methodological approach to examine these plans and compare across topics has also remained quite consistent among the articles found/selected for this review. The general methodological approach utilized in the articles consisted of the following:

(1) collecting a series of published documents that address the topics, regions, or interventions of interest to study ${ }^{1}$;

(2) developing an evaluation instrument that describes discrete elements of plan documents representing the ideas, concepts, theories, practices, or processes that are under examination;

\footnotetext{
${ }^{1}$ As described in Berke and Godschalk (2009), research design can greatly influence the plan sample selection. For example, cross sectional samples describe characteristics of plans over a spatial or organizational scale or to describe the quality of plans, however this approach limits researchers' ability to control for factors. Comparative research design selects plan documents where an intervention of interest is present and not present, however this approach assumes a priori that these documents can be selected and assessed accurately in order to determine the effect of the intervention. A third approach is utilizing a comparative research design with time series, whereby pre- and postintervention periods in multiple plan locations are examined.
} 
(3) utilizing qualitative content analysis through the use of multiple independent document reviewers; and

(4) analyzing the results using various qualitative, descriptive, or statistical methods to test study hypotheses or describe commonalities and differences in elements observed in the set of plans (Berke and Godschalk 2009).

Specific plan evaluation instruments varied across the studies examined. However, a common set of principle criteria were observed across the studies reviewed. These plan principles are described in Table $3 .^{2}$

Table 3. Plan principles for evaluation methodology

\begin{tabular}{|l|l|}
\hline Plan Principle & Description \\
\hline Goal Setting & $\begin{array}{l}\text { Statements or descriptions that reflect public values for future } \\
\text { desired conditions. These may be vision statements, goals and } \\
\text { objectives statements, plan purpose descriptions, or success } \\
\text { criteria. }\end{array}$ \\
\hline $\begin{array}{l}\text { Fact Base (including } \\
\text { handling uncertainty) }\end{array}$ & $\begin{array}{l}\text { Empirical evidence or information that describes present or } \\
\text { expected future conditions. This includes information about } \\
\text { hazards, climate change impacts, vulnerability or risk } \\
\text { assessment, information about the built environment including } \\
\text { information about development patterns and land use, } \\
\text { information about vulnerable populations, information about } \\
\text { natural systems, and economic conditions. }\end{array}$ \\
\hline $\begin{array}{l}\text { Uncertainty is considered a separate plan principle in some } \\
\text { studies, however the methods to assess and describe uncertainty } \\
\text { and the choices for how to report uncertainty, apply to any of } \\
\text { the fact base elements. }\end{array}$ \\
\hline
\end{tabular}

\footnotetext{
${ }^{2}$ Based upon Berke and Godschalk (2009), modified by Woodruff and Stults (2016), and term description adjusted
} based upon other articles reviewed in the annotated bibliography. 


\begin{tabular}{|c|c|}
\hline Plan Principle & Description \\
\hline $\begin{array}{l}\text { Strategies, policies, } \\
\text { solutions }\end{array}$ & $\begin{array}{l}\text { Specific information that can be used to guide decisions on } \\
\text { actions to achieve the plan goals. These elements can include a } \\
\text { wide variety of elements, such as design for the built } \\
\text { environment and infrastructure (e.g., building codes, design } \\
\text { requirements), land use, information dissemination and } \\
\text { awareness actions (e.g., labeling, disclosure requirements, } \\
\text { signage), preventative actions (e.g., property acquisition), } \\
\text { incentives, financial and technical assistance, administrative } \\
\text { requirements or capacity building. This may also include the } \\
\text { specification of decision making criteria, a decision making } \\
\text { process, or methodology. }\end{array}$ \\
\hline Public participation & $\begin{array}{l}\text { Recognition and involvement of actors, stakeholders, and } \\
\text { interested parties in the plan development process and } \\
\text { implementation. This involves descriptions of planning } \\
\text { processes that involve stakeholders, may be a participatory } \\
\text { planning process, steps to identify individuals or groups of } \\
\text { interest, their roles in plan preparation, and descriptions of their } \\
\text { involvement in implementation and updates. }\end{array}$ \\
\hline Organizational coordination & $\begin{array}{l}\text { Information or statements that indicate articulated needs for } \\
\text { interorganizational coordination of actions. This includes } \\
\text { coordination with other organizations that may provide } \\
\text { information or resources, coordination of other organizations on } \\
\text { goals, objectives, actions, and resources. Intergovernmental } \\
\text { coordination, such as across local government departments and } \\
\text { offices, is considered. }\end{array}$ \\
\hline $\begin{array}{l}\text { Implementation, monitoring, } \\
\text { and evaluation }\end{array}$ & $\begin{array}{l}\text { Guidance, commitments, timelines, funding sources, or other } \\
\text { information necessary to indicate how the plan will be } \\
\text { implemented. Indicators of objectives (e.g., quantitative } \\
\text { metrics) to assess implementation progress are included. } \\
\text { Monitoring also includes indicators that can be used } \\
\text { retrospectively to assess efficacy of implemented strategies, } \\
\text { policies, or solutions. }\end{array}$ \\
\hline
\end{tabular}




\section{Plan Evaluation Study Findings}

While the topical focus of planning evaluation evolved in the articles reviewed, the general evaluation objectives have not. Plan evaluation studies consistently examine the influence of community characteristics on the quality of plans. These studies theorize that underlying community characteristics have an influence on the capacity, process, or topics considered in a planning process, thereby influencing the quality of plans. These community characteristics include social and demographic factors, community economic and growth factors, the capacity of local government agencies to conduct and design planning processes, the involvement of community members in a planning process, and financial or budgetary inputs. The studies reviewed describe the relative influence of external interventions such as state level planning mandates (e.g., requirements for plan publication), technical assistance or financial assistance, intragovernmental or interorganizational (e.g., regional government, non-governmental organizations, private sector) coordination, and other policy mandates (e.g., environmental protection). Internal factors are also examined, including the use or presence of a planning department official on the plan development team and consistency between a community's plans. Through the exploration of these community characteristics as variables influencing plan quality, studies examine the relative contribution or importance of each of these factors, and develop recommendations for improvements in the practice of local community plan development (i.e., community internal modifications) or through modification to external interventions (e.g., regulatory policy, legislation, technical assistance, financial assistance).

Across the topics of plan quality assessment studies reviewed, there were a number of overarching findings that could be observed or generalized. For studies that evaluate plan quality through qualitative content analysis of plan document elements or through the use of a comparative research design (see following discussion on plan evaluation methodology), the following elements were observed to result in higher plan quality:

- Plans that describe a rigorous process for the establishment of goals and measurable objectives.

- Internal factors such as the presence of planners or staff from planning departments.

- External factors, such as the presence of state mandates for developing plans. (However, there were observed differences in the relative positive or negative influence of how mandates were implemented, such as whether the mandate was implemented through a requirement or through the use of an incentive such as technical assistance or financial incentives).

Across planning topics, the reviewed plan quality evaluation studies consistently described a series of factors where plans either scored poorly or areas were plans were not well developed. These included:

- Plan elements that described how data were selected for hazard or climate impacts, scenarios, or how information on projections of climate change impacts were selected. This also included a lack of description or consistent approach in describing the influence of climate change impacts on hazard intensity and frequency. 
- Descriptions of how hazard impacts and climate change impacts would be attributed to specific systems, sectors, and the related effects of sector specific vulnerabilities.

- Incorporation of uncertainty across plan factors (not only hazard or climate change projections).

- Various and inconsistent approaches being used to make judgements about future conditions (e.g., use of historical data and events, downscaled climate data, and/or current period extreme events).

- Collaboration, both intragovernmental and interorganizational, was not consistently observed to lead to high plan quality, however where mandates for coordination were present, coordination across plans and organizations generally led to higher quality plans (than those without coordination mandates). Further, some studies indicated that resilience plans scored relatively higher when they had a focus on the importance of public participation and engagement.

- Plan implementation, evaluation, and monitoring were all consistently observed to be lower scoring plan elements across topics and plans, indicating a focus on planning but a lack of content or lower quality information on how a plan would be effectively implemented and monitored.

\subsubsection{Terminology Concept Examinations}

In the articles reviewed, there remains much discussion on the interaction and application of the concepts of resilience of systems, the ability of systems to adapt (including and often primarily to climate change impacts), and the sustainability of systems. In the most general sense, the articles utilized these concepts as a means to describe system dynamics, whereby any type of system could be considered (e.g., socio-ecological systems, physical systems, natural systems) (Folke et al. 2010, Meerow and Newell 2015, Davidson et al. 2016, Romero-Lankao et al. 2016). Articles observed that in the context of natural hazards or the application of system stressors or shocks, (for the use of resilience and adaptation in particular), there are challenges with aligning the temporal scale of the use of these concepts. Specifically, hazard related use of terms generally refer to shorter temporal scales while adaptation is discussed in the context of longer temporal scales.

A related observation is the use of RAS terms to describe a "top-down" impact assessment approach, whereby information is collected to characterize future hazards, associated impacts, and support the selection and communication of options (Preston, Westaway, and Yuen 2011). In natural hazard or disaster risk reduction applications, there is disagreement on how the RAS terms are used to describe discrete elements of this planning approach (e.g., adaptation as climate change impacts on hazards), or rather if concepts should be integrated into all aspects of planning (e.g., adaptation as a theoretical framework for modifying all aspects of planning) (Koliou et al. 2020, B Perkins 2007, Birkmann and von Teichman 2010, Lei et al. 2014). Other articles observed that at all three terms are being used in an increasingly normative context, as desirable traits or practices rather than a measurable characteristic of a system or a system state (Moser et al. 2019, Woodruff et al. 2018, Folke 2006, Romero-Lankao et al. 2016). 
For resilience, conceptual discussions observed in the articles place an emphasis on urban resilience and recognize that previously there have been inconsistencies and ambiguities with specific definitions put forward. Notable characteristics or observed uses of resilience as a term presented in the articles reviewed, include: resilience as a concept to describe and understand the capacity of ecosystems to remain in a certain state when subjected to perturbations (Holling 1973, Gunderson 2000, Folke 2006, Folke et al. 2010, Scheffer 2009); its use to describe a system trait, a process or outcome; to describe an approach for addressing and dealing with uncertainty; and as a normative concept (Moser et al. 2019). System and process traits such as robustness, redundancy, diversity, inclusivity, adaptive capacity, adaptability, and flexibility are considered characteristics of urban systems resilience (Davidson et al. 2016, Meerow and Stults 2016).

For sustainability, there was a discussion in articles about the linkage between actions taken locally being connected to a larger organizational or spatial scale (e.g., community scale action contributing to global action), recognition that actions taken within the context of the planning unit have broader implications, contexts, or influence, representing a temporal connection between actions or resource use affecting future conditions and outcomes, and a strong topical relationship to environmental issues and natural systems (Berke and Conroy 2000). The articles presented discussions of sustainability related to environmental or ecological objectives (Romero-Lankao et al. 2016). Sustainability has been described as a planning objective related to ecological systems that requires a structured decision making process to assess and address short term and long term environmental impacts, including the effects and impacts of climate change (Lei et al. 2014). Other interpretations begin to merge sustainability with the terms of resilience and adaptation (Preston, Westaway, and Yuen 2011).

For adaptation, the discussion was generally presented in the context of addressing, planning for, or mitigating the impacts of climate change (Woodruff et al. 2018, Stults and Woodruff 2017). However, as presented in the opening discussion of this section, the ability of a system to adapt to changing conditions is also considered a characteristic or trait of resilience. Traits associated with adaptation describe the ability of a system to absorb shocks and then "bounce back" to a state or condition of prior function (Meerow and Stults 2016, Moser et al. 2019). Retrospective analyses of adaptation activities, in the context of hazard mitigation, observe similar characteristics by finding that adaptation activities reflect an objective of sustaining and protecting existing activities, rather than encouraging the capacity for long term change (Hu et al. 2018, Eakin and Patt 2011). Broader system interpretations of adaptation consider that systems that have the characteristics of adaptability can learn, adapt, and build resilience when internal or external drivers or shocks are imposed on the system, in order for the system to maintain its current trajectory.

\subsubsection{State of Practice, Implementation, or Research Examinations}

The articles reviewed that examine the state of practice, implementation, or research related to resilience, adaptation, and sustainability (RAS) planning provide insights into how concepts that 
have been discussed in the prior sections in an evaluative or conceptual context are implemented in practice. Reviews of RAS planning guidance documents were limited in the articles reviewed, but observations indicated that in practice these terms are often used interchangeably and distinctions between the terms as description of planning objectives or qualities of the planning process were not made.

Regardless of the terms used or characteristics of planning processes identified in the articles reviewed, there remain gaps in support of the practice of incorporating climate change impacts and projections in planning processes, both as a component of assessing the impacts on systems or individuals and as an integral principle or concept in the planning process. This is also true for research applications. There are needs for assembling and communicating information on climate change impacts in a useful and decision relevant context. This applies to various planning objectives, including ongoing research needs for assessing the impacts of climate change on infrastructure systems and how these effects can adversely affect systems that are interdependent upon one another.

\subsection{Future Work}

In the prior sections, a number of characteristics were identified that describe resilient, adaptive, or sustainable systems. These characteristics are useful for understanding, measuring, and potentially quantifying elements of planned systems. However, there remain research gaps in how to describe and model the relationships between physical systems (e.g., infrastructure) and social and economic systems that are affected by planning processes. These include describing the relationships between systems, describing how interventions in one system may affect another, and how the decisions of governmental bodies (e.g., planning processes, plan implementation) or individual decisions may affect overall system function (e.g., individual function substitution, such as transportation mode switching).

The selected articles' results and conclusions present several areas of potential future research on the intersection of planning objectives of resilience, adaptation, and sustainability. The scholarly body of work on planning evaluation considers various planning objectives, but only until recently has begun considering how the intersection of these objectives may affect planning outcomes. As observed in the literature review and in the experience of the implementation of NIST's Community Resilience Planning Guide (National Institute of Standards and Technology 2016), RAS objectives may be concurrently expressed. However, there remains a need to better understand and advance how multiple RAS objectives can be best integrated into planning, to examine methods or practices that increase the quality of solutions identified, and to improve the chances of successful plan implementation.

Plan assessment articles consistently found that plans scored poorly on implementation, monitoring, and evaluation principles, indicating a lack of inclusion or lower-quality information being provided on these topics. There are likely many factors leading to these relatively lower scores (and associated quality), including the alignment of incentives or responsibilities for plan authors to develop methods that transparently track, publish, and report on plan implementation. Without the ability for future implementation actions to be attributed back to plan elements, a 
significant gap remains in understanding how plans effectively translate into action. Future efforts that examine or improve upon plan evaluation methods are needed to assess the efficacy of different resilience, sustainability, and adaptation planning processes.

The plan quality assessment articles selected for this review also highlighted a shortcoming in research design, namely in the methods used to collect document samples for evaluation. The articles described various approaches to collect planning documents that are published by local governments that met their criteria for evaluation. Documents selected for evaluation were most commonly identified through systematic online searches, supplemented by researchers' existing knowledge of planning efforts. Without a more complete, widely disseminated, and publicly available set of data (i.e., planning documents and outcome documentation) to draw from, the progress of future research studies in this area will be hindered. Future efforts that allow researchers to access planning documents and are organized in a consistent, transparent, and well documented manner would advance plan quality assessment efforts and implementation of tracking across all types of planning objectives, including resilience, adaptation, and sustainability objectives. 


\section{Conclusion}

In the United States, local governments have the primary responsibilities for planning for mitigation, response, and recovery from natural hazard events. While preparing for natural hazards, communities are undertaking planning processes that have objectives related to resilience, adaptation, and sustainability. This has resulted in a growth of scholarly work and research on local plans addressing RAS objectives with the goal of improving planning processes, incentives, policy, and the implementation of plans. This report examines research and analytical methodologies to assess local planning documents through the following two objectives: (1) providing a review of scholarly literature assessing or evaluating community scale or local scale planning for objectives related to RAS, and (2) informing the future development of an analytical methodology to assess the content of RAS planning guidance, instructions, and requirements for practice. The research in this Technical Note is intended to support a future assessment of community-focused RAS guidance and support research into RAS planners expectation for technical planning guidance and planning processes.

The results of the literature review present a generalized set of plan principles that can inform the development of a planning guidance assessment methodology: processes for goal setting, the presence of a fact base including accounting for uncertainty, the decision making process leading to the articulation of strategies, policies, or solutions supporting plan goals, processes for public participation, information on the need and process for organizational coordination (internal coordination and coordination with external organizations), and information, data collection, and processes to support plan implementation and subsequent monitoring and evaluation. Additionally, a discussion of terminology related to resilience, sustainability, and adaptation are included, indicating considerable overlap in the use and understanding of these terms and the increasing use of the terms in normative contexts as compared to their use as measurable traits.

Several areas of future work at the intersection of research and practice were identified, including development of a methodology for integrated planning assessment and needed advances in methodology plan for implementation, monitoring, and evaluation. Lastly, a systematic process for locating and accessing planning documents would improve future planning research studies, lead to increased comparability between studies, and contribute toward enhancing the quality of research outcomes and identified best practices. 


\section{References}

Adger, W. Neil, Terry P. Hughes, Carl Folke, Stephen R. Carpenter, and Johan Rockström. 2005. "Social-ecological resilience to coastal disasters." Science 309 (5737):1036-1039.

B Perkins, D. Ojima R. Corell. 2007. A Survey of Climate Change Adaptation Planning. Heinz Center.

Baker, Ingrid, Ann Peterson, Gregory Brown, and Clive McAlpine. 2012. "Local government response to the impacts of climate change: An evaluation of local climate adaptation plans." Landscape and Urban Planning 107:127-136. doi: 10.1016/j.landurbplan.2012.05.009.

Berke, P., G. Smith, and W. Lyles. 2012. "Planning for Resiliency: Evaluation of State Hazard Mitigation Plans under the Disaster Mitigation Act." Natural Hazards Review 13 (2):139-149. doi: 10.1061/(asce)nh.1527-6996.0000063.

Berke, Philip, John Cooper, Meghan Aminto, Shannon Grabich, and Jennifer Horney. 2014. "Adaptive Planning for Disaster Recovery and Resiliency: An Evaluation of 87 Local Recovery Plans in Eight States." Journal of the American Planning Association 80 (4):310-323. doi: 10.1080/01944363.2014.976585.

Berke, Philip, and David Godschalk. 2009. "Searching for the Good Plan: A Meta-Analysis of Plan Quality Studies." Journal of Planning Literature. doi: 10.1177/0885412208327014.

Berke, Philip R. 2008. "The evolution of green community planning, scholarship, and practice: an introduction to the special issue." Journal of the American Planning Association 74 (4):393-407.

Berke, Philip R., and Maria Manta Conroy. 2000. "Are We Planning for Sustainable Development?" Journal of the American Planning Association 66 (1):21-33. doi: 10.1080/01944360008976081.

Berke, Philip R., Ward Lyles, and Gavin Smith. 2014. "Impacts of Federal and State Hazard Mitigation Policies on Local Land Use Policy." Journal of Planning Education and Research. doi: 10.1177/0739456X13517004. 
Bierbaum, R., J. B. Smith, A. Lee, M. Blair, L. Carter, F. S. Chapin, P. Fleming, S. Ruffo, M. Stults, S. McNeeley, E. Wasley, and L. Verduzco. 2013. "A comprehensive review of climate adaptation in the United States: more than before, but less than needed." Mitigation and Adaptation Strategies for Global Change 18 (3):361-406. doi: 10.1007/s1 1027-012-9423-1.

Birkmann, Jörn, and Korinna von Teichman. 2010. "Integrating disaster risk reduction and climate change adaptation: key challenges_-scales, knowledge, and norms." Sustainability Science 5 (2):171-184. doi: 10.1007/s11625-010-0108-y.

Bullard, Robert D. 1994. "Overcoming racism in environmental decisionmaking." Environment: Science and policy for sustainable development 36 (4):10-44.

Cutter, Susan L., Bryan J. Boruff, and W. Lynn Shirley. 2003. "Social vulnerability to environmental hazards." Social science quarterly 84 (2):242-261.

Cutter, Susan L., and Christina Finch. 2008. "Temporal and spatial changes in social vulnerability to natural hazards." Proceedings of the National Academy of Sciences 105 (7):2301-2306.

Davidson, J. L., C. Jacobson, A. Lyth, A. Dedekorkut-Howes, C. L. Baldwin, J. C. Ellison, N. J. Holbrook, M. J. Howes, S. Serrao-Neumann, L. Singh-Peterson, and T. F. Smith. 2016. "Interrogating resilience: toward a typology to improve its operationalization." Ecology and Society 21 (2). doi: 10.5751/es-08450-210227.

Davoudi, Simin, Keith Shaw, L. Jamila Haider, Allyson E. Quinlan, Garry D. Peterson, Cathy Wilkinson, Hartmut Fünfgeld, Darryn McEvoy, and Libby Porter. 2012. "Resilience: a bridging concept or a dead end?" Planning theory \& practice 13 (2):299-333.

Dillard, Maria K., Jennifer F. Helgeson, and Stephen A. Cauffman. 2018. "Implementation of the NIST Community Resilience Planning Guide for Buildings and Infrastructure Systems."

Eakin, Hallie C., and Anthony Patt. 2011. "Are adaptation studies effective, and what can enhance their practical impact?" WIREs Climate Change 2 (2):141-153. doi: 10.1002/wcc. 100 .

EDA. 2020. "Comprehensive Economic Development Strategy (CEDS)." Comprehensive Economic Development Strategy (CEDS). 
Feinberg, Daniel S., and Clare M. Ryan. 2020. "Evaluating the Quality and Implementation of Hazard Mitigation Plans in Coastal Washington State." Natural Hazards Review 21 (2):04020013. doi: 10.1061/(ASCE)NH.1527-6996.0000372.

FEMA. 2020a. "Building Resilient Infrastructure and Communities (BRIC) | FEMA.gov." Building Resilient Infrastructure and Communities (BRIC).

FEMA. 2020b. "Hazard Mitigation Grants." Hazard Mitigation Grants.

Folke, Carl. 2006. "Resilience: The emergence of a perspective for social-ecological systems analyses." Global Environmental Change 16 (3):253-267. doi: 10.1016/j.gloenvcha.2006.04.002.

Folke, Carl, Stephen R. Carpenter, Brian Walker, Marten Scheffer, Terry Chapin, and Johan Rockstrom. 2010. "Resilience Thinking: Integrating Resilience, Adaptability and Transformability." Ecology and Society 15 (4):20. doi: 10.5751/es-03610-150420.

Folke, Carl, Steve Carpenter, Thomas Elmqvist, Lance Gunderson, Crawford S. Holling, and Brian Walker. 2002. "Resilience and sustainable development: building adaptive capacity in a world of transformations." AMBIO: A journal of the human environment 31 (5):437440.

Godschalk, David, Timothy Beatley, Philip Berke, David Brower, and Edward J. Kaiser. 1998. Natural hazard mitigation: Recasting disaster policy and planning: Island Press.

Gunderson, Lance H. 2000. "Ecological resilience-in theory and application." Annual review of ecology and systematics 31 (1):425-439.

Holling, C. S. 1973. "Resilience and Stability of Ecological Systems." Annual Review of Ecology and Systematics 4 (1):1-23. doi: 10.1146/annurev.es.04.110173.000245.

Holling, Crawford Stanley. 1996. "Engineering resilience versus ecological resilience." Engineering within ecological constraints 31 (1996):32.

Hu, Q., Z. H. Tang, L. Zhang, Y. Y. Xu, X. L. Wu, and L. G. Zhang. 2018. "Evaluating climate change adaptation efforts on the US 50 states' hazard mitigation plans." Natural Hazards 92 (2):783-804. doi: 10.1007/s11069-018-3225-z.

HUD. 2020a. "CDBG-DR: Community Development Block Grant Disaster Recovery Program HUD Exchange." Community Development Block Grant Disaster Recovery Program. HUD. 2020b. "CDBG-MIT: Community Development Block Grant Mitigation Program - HUD Exchange." Community Development Block Grant Mitigation Program. 
IPCC. 2001. Third Assessment Report (AR3). Cambridge: Cambridge University Press.

Kasperson, Jeanne X., and Roger E. Kasperson. 2005. The Social Contours of Risk: Risk analysis, corporations \& the globalization of risk. Vol. 2: Earthscan.

Koliou, Maria, John W. van de Lindt, Therese P. McAllister, Bruce R. Ellingwood, Maria Dillard, and Harvey Cutler. 2020. "State of the research in community resilience: progress and challenges." Sustainable and Resilient Infrastructure 5 (3):131-151. doi: 10.1080/23789689.2017.1418547.

Lei, Yongdeng, Jing'ai Wang, Yaojie Yue, Hongjian Zhou, and Weixia Yin. 2014. "Rethinking the relationships of vulnerability, resilience, and adaptation from a disaster risk perspective." Natural Hazards 70 (1):609-627. doi: 10.1007/s11069-013-0831-7.

Lyles, W., P. Berke, and G. Smith. 2014. "A comparison of local hazard mitigation plan quality in six states, USA." Landscape and Urban Planning 122:89-99. doi: 10.1016/j.landurbplan.2013.11.010.

Lyles, Ward, and Mark Stevens. 2014. "Plan Quality Evaluation 1994-2012: Growth and Contributions, Limitations, and New Directions." Journal of Planning Education and Research. doi: 10.1177/0739456X14549752.

Marshall, Nadine A., N. A. Marshall, P. A. Marshall, Jerker Tamelander, David Obura, Delphine Malleret-King, and J. E. Cinner. 2010. A framework for social adaptation to climate change: sustaining tropical coastal communitites [sic] and industries: IUCN.

Meerow, S., and J. P. Newell. 2015. "Resilience and Complexity A Bibliometric Review and Prospects for Industrial Ecology." Journal of Industrial Ecology 19 (2):236-251. doi: 10.1111/jiec. 12252.

Meerow, S., J. P. Newell, and M. Stults. 2016. "Defining urban resilience: A review." Landscape and Urban Planning 147:38-49. doi: 10.1016/j.landurbplan.2015.11.011.

Meerow, Sara, and Melissa Stults. 2016. "Comparing Conceptualizations of Urban Climate Resilience in Theory and Practice." Sustainability 8 (7):701. doi: 10.3390/su8070701.

Mileti, Dennis. 1999. Disasters by design: A reassessment of natural hazards in the United States: Joseph Henry Press.

Moser, S., S. Meerow, J. Arnott, and E. Jack-Scott. 2019. "The turbulent world of resilience: interpretations and themes for transdisciplinary dialogue." Climatic Change 153 (12):21-40. doi: 10.1007/s10584-018-2358-0. 
National Institute of Standards and Technology. 2016. Community Resilience Planning Guide for Buildings and Infrastructure Systems.

Paton, Douglas, and David Johnston. 2001. "Disasters and communities: vulnerability, resilience and preparedness." Disaster Prevention and Management: An International Journal.

Preston, Benjamin L., Richard M. Westaway, and Emma J. Yuen. 2011. "Climate adaptation planning in practice: an evaluation of adaptation plans from three developed nations." Mitigation and Adaptation Strategies for Global Change 16 (4):407-438. doi: 10.1007/s11027-010-9270-x.

Romero-Lankao, P., D. M. Gnatz, O. Wilhelmi, and M. Hayden. 2016. "Urban Sustainability and Resilience: From Theory to Practice." Sustainability 8 (12). doi: 10.3390/su8121224.

Rose, Adam, and Shu-Yi Liao. 2005. "Modeling regional economic resilience to disasters: A computable general equilibrium analysis of water service disruptions." Journal of Regional Science 45 (1):75-112.

Scheffer, Marten. 2009. Critical transitions in nature and society. Vol. 16: Princeton University Press.

Schrock, Greg, Ellen M. Bassett, and Jamaal Green. 2015. "Pursuing Equity and Justice in a Changing Climate: Assessing Equity in Local Climate and Sustainability Plans in U.S. Cities." Journal of Planning Education and Research 35 (3):282-295. doi: $10.1177 / 0739456 X 15580022$.

Sellberg, My M., Cathy Wilkinson, and Garry D. Peterson. 2015. "Resilience assessment: a useful approach to navigate urban sustainability challenges." Ecology and Society 20 (1):43. doi: 10.5751/ES-07258-200143.

Stults, M., and S. C. Woodruff. 2017. "Looking under the hood of local adaptation plans: shedding light on the actions prioritized to build local resilience to climate change." Mitigation and Adaptation Strategies for Global Change 22 (8):1249-1279. doi: 10.1007/s11027-016-9725-9.

The Nature Conservancy. 2020. "Coastal Resilience." https://coastalresilience.org/. The Rockefeller Foundation. 2020. "100 Resilient Cities." 100 Resilient Cities. U. S. Global Change Research Program. 2020. "U.S. Climate Resilience Toolkit | U.S. Climate Resilience Toolkit." US Climate Resilience Toolkit. 
Walker, Brian, Crawford S. Holling, Stephen R. Carpenter, and Ann Kinzig. 2004. "Resilience, adaptability and transformability in social-ecological systems." Ecology and society 9 (2).

Wied, M., J. Oehmen, and T. Welo. 2020. "Conceptualizing resilience in engineering systems: An analysis of the literature." Systems Engineering 23 (1):3-13. doi: 10.1002/sys.21491.

Woodruff, S. C., and M. Stults. 2016. "Numerous strategies but limited implementation guidance in US local adaptation plans." Nature Climate Change 6 (8):796-+. doi: 10.1038/nclimate3012.

Woodruff, Sierra C., Sara Meerow, Missy Stults, and Chandler Wilkins. 2018. "Adaptation to Resilience Planning: Alternative Pathways to Prepare for Climate Change." Journal of Planning Education and Research:0739456X18801057. doi:

10.1177/0739456X18801057.

Zhou, Hongjian, Jing'ai Wang, Jinhong Wan, and Huicong Jia. 2010. "Resilience to natural hazards: a geographic perspective." Natural Hazards 53 (1):21-41. doi: 10.1007/s11069009-9407-y. 


\section{Appendix A - Full Listing of Articles Identified in Web of Science Query}

Araos, Malcolm, Lea Berrang-Ford, James D. Ford, Stephanie E. Austin, Robbert

Biesbroek, and Alexandra Lesnikowski. 2016. "Climate Change Adaptation Planning in Large Cities: A Systematic Global Assessment." Environmental Science and Policy 66 (December): 375-82. https://doi.org/10.1016/j.envsci.2016.06.009.

Azevedo, Isabel, and Vitor M. S. Leal. 2017. "Methodologies for the Evaluation of Local Climate Change Mitigation Actions: A Review.” Renewable and Sustainable Energy Reviews 79 (November): 681-90. https://doi.org/10.1016/j.rser.2017.05.100.

B Perkins, D Ojima, R Corell. 2007. "A Survey of Climate Change Adaptation Planning."

Heinz Center. https://www.coolrooftoolkit.org/wpcontent/uploads/2012/04/SurveyCCAdapatationPlanning.pdf.

Baker, Ingrid, Ann Peterson, Gregory Brown, and Clive Mcalpine. 2012. "Local Government Response to the Impacts of Climate Change: An Evaluation of Local Climate Adaptation Plans." Landscape and Urban Planning 107 (August): 127-136. https://doi.org/10.1016/j.landurbplan.2012.05.009.

Berke, P., G. Smith, and W. Lyles. 2012. "Planning for Resiliency: Evaluation of State Hazard Mitigation Plans under the Disaster Mitigation Act." Natural Hazards Review 13 (2): 139-49. https://doi.org/10.1061/(asce)nh.1527-6996.0000063.

Berke, Philip, John Cooper, Meghan Aminto, Shannon Grabich, and Jennifer Horney. 2014. "Adaptive Planning for Disaster Recovery and Resiliency: An Evaluation of 87 Local Recovery Plans in Eight States." Journal of the American Planning Association 80 (4): 310-23. https://doi.org/10.1080/01944363.2014.976585.

Berke, Philip, and David Godschalk. 2009. "Searching for the Good Plan: A Meta-Analysis of Plan Quality Studies.” Journal of Planning Literature, February. https://doi.org/10.1177/0885412208327014.

Berke, Philip R., and Maria Manta Conroy. 2000. "Are We Planning for Sustainable Development?" Journal of the American Planning Association 66 (1): 21-33. https://doi.org/10.1080/01944360008976081.

Berke, Philip R., Ward Lyles, and Gavin Smith. 2014. "Impacts of Federal and State Hazard Mitigation Policies on Local Land Use Policy:" Journal of Planning Education and Research, January. https://doi.org/10.1177/0739456X13517004.

Biagini, B., R. Bierbaum, M. Stults, S. Dobardzic, and S. M. McNeeley. 2014. “A Typology of Adaptation Actions: A Global Look at Climate Adaptation Actions Financed through 
the Global Environment Facility." Global Environmental Change-Human and Policy Dimensions 25 (March): 97-108. https://doi.org/10.1016/j.gloenvcha.2014.01.003.

Bierbaum, R., J. B. Smith, A. Lee, M. Blair, L. Carter, F. S. Chapin, P. Fleming, et al. 2013. "A Comprehensive Review of Climate Adaptation in the United States: More than before, but Less than Needed." Mitigation and Adaptation Strategies for Global Change 18 (3): 361-406. https://doi.org/10.1007/s11027-012-9423-1.

Biesbroek, R., L. Berrang-Ford, J. D. Ford, A. Tanabe, S. E. Austin, and A. Lesnikowski. 2018. "Data, Concepts and Methods for Large-n Comparative Climate Change Adaptation Policy Research: A Systematic Literature Review." Wiley Interdisciplinary Reviews-Climate Change 9 (6): 15. https://doi.org/10.1002/wcc.548.

Birkmann, Jörn, and Korinna von Teichman. 2010. "Integrating Disaster Risk Reduction and Climate Change Adaptation: Key Challenges-Scales, Knowledge, and Norms." Sustainability Science 5 (2): 171-84. https://doi.org/10.1007/s11625-010-0108-y.

Carpenter, Steve, Brian Walker, J. Marty Anderies, and Nick Abel. 2001. "From Metaphor to Measurement: Resilience of What to What?" Ecosystems 4 (8): 765-81.

https://doi.org/10.1007/s10021-001-0045-9.

Cutter, Susan L., Lindsey Barnes, Melissa Berry, Christopher Burton, Elijah Evans, Eric Tate, and Jennifer Webb. 2008. "A Place-Based Model for Understanding Community Resilience to Natural Disasters." Global Environmental Change 18 (4): 598-606. https://doi.org/10.1016/j.gloenvcha.2008.07.013.

Davidson, J. L., C. Jacobson, A. Lyth, A. Dedekorkut-Howes, C. L. Baldwin, J. C. Ellison, N. J. Holbrook, et al. 2016. "Interrogating Resilience: Toward a Typology to Improve Its Operationalization.” Ecology and Society 21 (2). https://doi.org/10.5751/es-08450210227.

Doorn, Neelke, Paolo Gardoni, and Colleen Murphy. 2019. "A Multidisciplinary Definition and Evaluation of Resilience: The Role of Social Justice in Defining Resilience." Sustainable and Resilient Infrastructure 4 (3): 112-23. https://doi.org/10.1080/23789689.2018.1428162.

Eakin, Hallie C., and Anthony Patt. 2011. "Are Adaptation Studies Effective, and What Can Enhance Their Practical Impact?” WIREs Climate Change 2 (2): 141-53. https://doi.org/10.1002/wcc.100.

Feinberg, Daniel S., and Clare M. Ryan. 2020. "Evaluating the Quality and Implementation of Hazard Mitigation Plans in Coastal Washington State." Natural Hazards Review 21 (2): 04020013. https://doi.org/10.1061/(ASCE)NH.1527-6996.0000372. 
Folke, Carl. 2006. "Resilience: The Emergence of a Perspective for Social-Ecological Systems Analyses." Global Environmental Change, Resilience, Vulnerability, and Adaptation: A Cross-Cutting Theme of the International Human Dimensions Programme on Global Environmental Change, 16 (3): 253-67.

https://doi.org/10.1016/j.gloenvcha.2006.04.002.

Folke, Carl, Stephen R. Carpenter, Brian Walker, Marten Scheffer, Terry Chapin, and Johan Rockstrom. 2010. "Resilience Thinking: Integrating Resilience, Adaptability and Transformability." Ecology and Society 15 (4): 20. https://doi.org/10.5751/es-03610$\underline{150420 .}$.

Füssel, Hans-Martin. 2008. “Assessing Adaptation to the Health Risks of Climate Change: What Guidance Can Existing Frameworks Provide?” International Journal of Environmental Health Research 18 (1): 37-63.

https://doi.org/10.1080/09603120701358416.

Gonick, S. A., and N. A. Errett. 2018. "Integrating Climate Change into Hazard Mitigation Planning: A Survey of State Hazard Mitigation Officers." Sustainability 10 (11). https://doi.org/10.3390/su10114150.

Holling, C S. 1973. "Resilience and Stability of Ecological Systems." Annual Review of Ecology and Systematics 4 (1): 1-23.

https://doi.org/10.1146/annurev.es.04.110173.000245.

Hu, Q., Z. H. Tang, M. Shulski, N. Umphlett, T. Abdel-Monem, and F. E. Uhlarik. 2018. “An Examination of Midwestern US Cities' Preparedness for Climate Change and Extreme Hazards." Natural Hazards 94 (2): 777-800. https://doi.org/10.1007/s11069018-3420-y.

Hu, Q., Z. H. Tang, L. Zhang, Y. Y. Xu, X. L. Wu, and L. G. Zhang. 2018. "Evaluating Climate Change Adaptation Efforts on the US 50 States' Hazard Mitigation Plans." Natural Hazards 92 (2): 783-804. https://doi.org/10.1007/s11069-018-3225-z.

Karmele Herranz-Pascual, M., Jose Luis Eguiguren-Garcia, Rocio Proy-Rodriguez, and Jesus Cuadrado-Rojo. 2013. "New Tools to Support Decision Making in Urban Planning. Model of Sustainability Assessment of Municipal Action Plans." Dyna 88 (4): 462-72. https://doi.org/10.6036/5427.

Keenan, J. M. 2018. "Types and Forms of Resilience in Local Planning in the US: Who Does What?" Environmental Science and Policy 88 (October): 116-23. https://doi.org/10.1016/j.envsci.2018.06.015.

Kim, Hwayoung, and Ryuji Kakimoto. 2016. "An International Comparative Analysis of Local Hazard Mitigation Plan Evaluation for Flood The USA, Japan and Korea." 
International Journal of Disaster Resilience in the Built Environment 7 (4): 406-19. https://doi.org/10.1108/IJDRBE-07-2014-0056.

Koliou, Maria, John W. van de Lindt, Therese P. McAllister, Bruce R. Ellingwood, Maria Dillard, and Harvey Cutler. 2020. "State of the Research in Community Resilience: Progress and Challenges." Sustainable and Resilient Infrastructure 5 (3): 131-51. https://doi.org/10.1080/23789689.2017.1418547.

Lei, Yongdeng, Jing'ai Wang, Yaojie Yue, Hongjian Zhou, and Weixia Yin. 2014.

"Rethinking the Relationships of Vulnerability, Resilience, and Adaptation from a Disaster Risk Perspective.” Natural Hazards 70 (1): 609-27.

https://doi.org/10.1007/s11069-013-0831-7.

Lyles, W., P. Berke, and G. Smith. 2014. "A Comparison of Local Hazard Mitigation Plan Quality in Six States, USA." Landscape and Urban Planning 122 (February): 89-99. https://doi.org/10.1016/j.landurbplan.2013.11.010.

Lyles, Ward, and Mark Stevens. 2014. "Plan Quality Evaluation 1994-2012: Growth and Contributions, Limitations, and New Directions." Journal of Planning Education and Research, October. https://doi.org/10.1177/0739456X14549752.

Meerow, S., and J. P. Newell. 2015. "Resilience and Complexity A Bibliometric Review and Prospects for Industrial Ecology." Journal of Industrial Ecology 19 (2): 236-51. https://doi.org/10.1111/jiec.12252.

Meerow, S., J. P. Newell, and M. Stults. 2016. "Defining Urban Resilience: A Review." Landscape and Urban Planning 147 (March): 38-49. https://doi.org/10.1016/j.landurbplan.2015.11.011.

Meerow, Sara, and Melissa Stults. 2016. "Comparing Conceptualizations of Urban Climate Resilience in Theory and Practice.” Sustainability 8 (7): 701. https://doi.org/10.3390/su8070701.

Mimura N, Pulwarty RS, Duc DM, Elshinnawy I, Redsteer MH, Huang HQ, Nkem JN, Rodriguez RAS, David. n.d. "IPCC AR4 WG2 15 - Adaptation Planning and Implementation."

Moser, S., S. Meerow, J. Arnott, and E. Jack-Scott. 2019. "The Turbulent World of Resilience: Interpretations and Themes for Transdisciplinary Dialogue." Climatic Change 153 (1-2): 21-40. https://doi.org/10.1007/s10584-018-2358-0.

Moser, Susanne. 2009. "Making a Difference on the Ground: The Challenge of Demonstrating the Effectiveness of Decision Support." Climatic Change 95 (1): 11. https://doi.org/10.1007/s10584-008-9539-1. 
Nordgren, J., M. Stults, and S. Meerow. 2016. "Supporting Local Climate Change Adaptation: Where We Are and Where We Need to Go." Environmental Science and Policy 66 (December): 344-52. https://doi.org/10.1016/j.envsci.2016.05.006.

Preston, Benjamin L., Richard M. Westaway, and Emma J. Yuen. 2011. “Climate Adaptation Planning in Practice: An Evaluation of Adaptation Plans from Three Developed Nations." Mitigation and Adaptation Strategies for Global Change 16 (4): 407-38. https://doi.org/10.1007/s11027-010-9270-X.

Romero-Lankao, P., D. M. Gnatz, O. Wilhelmi, and M. Hayden. 2016. "Urban

Sustainability and Resilience: From Theory to Practice." Sustainability 8 (12).

https://doi.org/10.3390/su8121224.

Samuel, C., and L. K. Siebeneck. 2019. "Roles Revealed: An Examination of the Adopted Roles of Emergency Managers in Hazard Mitigation Planning and Strategy Implementation.” International Journal of Disaster Risk Reduction 39 (October). https://doi.org/10.1016/j.ijdrr.2019.101145.

Schrock, Greg, Ellen M. Bassett, and Jamaal Green. 2015. "Pursuing Equity and Justice in a Changing Climate: Assessing Equity in Local Climate and Sustainability Plans in U.S. Cities." Journal of Planning Education and Research 35 (3): 282-95.

https://doi.org/10.1177/0739456X15580022.

Scipioni, Antonio, Anna Mazzi, Filippo Zuliani, and Marco Mason. 2008. "The ISO 14031

Standard to Guide the Urban Sustainability Measurement Process: An Italian

Experience." Journal of Cleaner Production 16 (12): 1247-57.

https://doi.org/10.1016/j.jclepro.2007.06.013.

Sellberg, My M., Cathy Wilkinson, and Garry D. Peterson. 2015. "Resilience Assessment:

A Useful Approach to Navigate Urban Sustainability Challenges.” Ecology and Society 20 (1): 43. https://doi.org/10.5751/ES-07258-200143.

Serrao-Neumann, S., F. Crick, Harman Ben, G. Schuch, and D. L. Choy. 2015. "Maximising Synergies between Disaster Risk Reduction and Climate Change Adaptation: Potential Enablers for Improved Planning Outcomes.” Environmental Science and Policy 50 (June): 46-61. https://doi.org/10.1016/j.envsci.2015.01.017.

Singh-Peterson, Lila, Paul Salmon, Natassia Goode, and John Gallina. 2016. “An Evaluation

of the Community Disaster Resilience Scorecard Toolkit by Small, High-Risk

Communities on the Sunshine Coast." Natural Hazards 84 (1): 489-505.

https://doi.org/10.1007/s11069-016-2435-5.

Smith JB, Vogel JM, Cruce TL, Seidel S, Holsinger HA. 2010. "Adapting to Climate Change: A Call for Federal Leadership.” Pew Center on Global Climate Change. 
Smith, Joel B., Jason M. Vogel, and John E. Cromwell III. 2009. "An Architecture for Government Action on Adaptation to Climate Change. An Editorial Comment." Climatic Change 95 (1): 53-61. https://doi.org/10.1007/s10584-009-9623-1.

Stults, M., and S. C. Woodruff. 2017. "Looking under the Hood of Local Adaptation Plans: Shedding Light on the Actions Prioritized to Build Local Resilience to Climate Change." Mitigation and Adaptation Strategies for Global Change 22 (8): 1249-79. https://doi.org/10.1007/s11027-016-9725-9.

Tang, Zhenghong, Samuel D. Brody, Courtney Quinn, Liang Chang, and Ting Wei. 2010. "Moving from Agenda to Action: Evaluating Local Climate Change Action Plans." Journal of Environmental Planning and Management 53 (1): 41-62. https://doi.org/10.1080/09640560903399772.

Taylor, Zack, Joanne Fitzgibbons, and Carrie L. Mitchell. 2020. "Finding the Future in Policy Discourse: An Analysis of City Resilience Plans." Regional Studies 0 (0): 1-13. https://doi.org/10.1080/00343404.2020.1760235.

Webler, T., S. Tuler, K. Dow, J. Whitehead, and N. Kettle. 2016. "Design and Evaluation of a Local Analytic-Deliberative Process for Climate Adaptation Planning." Local Environment 21 (2): 166-88. https://doi.org/10.1080/13549839.2014.930425.

Westin, Alexandra Lavers, Yuliya Kalmykova, and Leonardo Rosado. 2019. "Method for Quantitative Evaluation of Sustainability Measures: A Systems Approach for Policy Prioritization.” Sustainability 11 (3): 734. https://doi.org/10.3390/su11030734.

Wied, M., J. Oehmen, and T. Welo. 2020. "Conceptualizing Resilience in Engineering Systems: An Analysis of the Literature." Systems Engineering 23 (1): 3-13. https://doi.org/10.1002/sys.21491.

Woodruff, S. C., and M. Stults. 2016. "Numerous Strategies but Limited Implementation Guidance in US Local Adaptation Plans.” Nature Climate Change 6 (8): 796-+. https://doi.org/10.1038/nclimate3012.

Woodruff, S. C., and P. Regan. 2019. "Quality of National Adaptation Plans and Opportunities for Improvement." Mitigation and Adaptation Strategies for Global Change 24 (1): 53-71. https://doi.org/10.1007/s11027-018-9794-z.

Woodruff, Sierra C., Sara Meerow, Missy Stults, and Chandler Wilkins. 2018. "Adaptation to Resilience Planning: Alternative Pathways to Prepare for Climate Change." Journal of Planning Education and Research, October, 0739456X18801057. https://doi.org/10.1177/0739456X18801057. 
Zhou, Hongjian, Jing'ai Wang, Jinhong Wan, and Huicong Jia. 2010. "Resilience to Natural Hazards: A Geographic Perspective.” Natural Hazards 53 (1): 21-41.

https://doi.org/10.1007/s11069-009-9407-y. 